\title{
Reactivation and Lytic Replication of Kaposi's Sarcoma-Associated Herpesvirus: An Update
}

\author{
Kawalpreet K. Aneja and Yan Yuan* \\ Department of Microbiology, University of Pennsylvania School of Dental Medicine, Philadelphia, PA, USA
}

The life cycle of Kaposi's sarcoma-associated herpesvirus (KSHV) consists of two phases, latent and lytic. The virus establishes latency as a strategy for avoiding host immune surveillance and fusing symbiotically with the host for lifetime persistent infection. However, latency can be disrupted and KSHV is reactivated for entry into the Iytic replication. Viral Iytic replication is crucial for efficient dissemination from its long-term reservoir to the sites of disease and for the spread of the virus to new hosts. The balance of these two phases in the KSHV life cycle is important for both the virus and the host and control of the switch between these two phases is extremely complex. Various environmental factors such as oxidative stress, hypoxia, and certain chemicals have been shown to switch KSHV from latency to lytic reactivation. Immunosuppression, unbalanced inflammatory cytokines, and other viral co-infections also lead to the

OPEN ACCESS

Edited by:

Michael Nevels,

University of St Andrews, UK

Reviewed by:

Chris Sullivan,

University of Texas at Austin, USA

Subhash C. Verma,

University of Nevada, Reno, USA

*Correspondence:

Yan Yuan

yuan2@pobox.upenn.edu

Specialty section:

This article was submitted to

Virology,

a section of the journal

Frontiers in Microbiology

Received: 30 November 2016

Accepted: 27 March 2017

Published: 20 April 2017

Citation:

Aneja KK and Yuan Y (2017) Reactivation and Lytic Replication of Kaposi's Sarcoma-Associated

Herpesvirus: An Update.

Front. Microbiol. 8:613.

doi: 10.3389/fmicb.2017.00613 reactivation of KSHV. This review article summarizes the current understanding of the initiation and regulation of KSHV reactivation and the mechanisms underlying the process of viral lytic replication. In particular, the central role of an immediate-early gene product RTA in KSHV reactivation has been extensively investigated. These studies revealed multiple layers of regulation in activation of RTA as well as the multifunctional roles of RTA in the lytic replication cascade. Epigenetic regulation is known as a critical layer of control for the switch of KSHV between latency and lytic replication. The viral non-coding RNA, PAN, was demonstrated to play a central role in the epigenetic regulation by serving as a guide RNA that brought chromatin remodeling enzymes to the promoters of RTA and other lytic genes. In addition, a novel dimension of regulation by microPeptides emerged and has been shown to regulate RTA expression at the protein level. Overall, extensive investigation of KSHV reactivation and lytic replication has revealed a sophisticated regulation network that controls the important events in KSHV life cycle.

\section{Keywords: Kaposi's sarcoma-associated herpesvirus (KSHV), human herpesvirus 8 (HHV-8), lytic replication, viral reactivation, Rta}

\section{INTRODUCTION}

Herpesviruses are extremely successful parasites. Once infected, the individual carries the virus for the rest of life. The success is attributable to the abilities of herpesvirus to (i) efficiently enter host cells, (ii) decisively establish life-long latent infection, and (iii) effectively reactivate upon stimulation from which progeny viruses can be propagated for dissemination within the host and 
transmission between individuals. Pharmaceutical intervention of any of the three steps can break the chain of viral life cycle and serve as antiviral strategies for treatment of virally associated human diseases or cancers. Achieving this goal relies on a thorough comprehension of the processes in the viral life cycle and the underlying mechanisms.

Kaposi's sarcoma-associated herpesvirus (KSHV), also termed human herpesvirus type 8 is a member of the human $\gamma$-herpesvirus family. It is an etiological agent of Kaposi's sarcoma (KS), a common AIDS-associated malignancy (Chang et al., 1994), as well as two lymphoproliferative diseases, namely primary effusion lymphoma and multicentric Castleman's disease (Antman and Chang, 2000; Giffin and Damania, 2014). Unique among herpesviruses, the lytic cycle of KSHV is not only required for the production of progeny viruses, but also contribute to the viral oncogenesis including the development of KS. Studies of $\mathrm{KSHV}$ in the last two decades have led to a great comprehension about reactivation and lytic replication of the virus including some common mechanisms shared by all herpesviruses and the unique features that contribute to the special life cycle of KSHV or gamma-herpesviruses as well as diseases specifically associated with KSHV. This review updates the current knowledge of the reactivation of latently infected $\mathrm{KSHV}$ and its lytic replication.

\section{TWO PHASES OF KSHV LIFE CYCLE AND THEIR BIOLOGICAL SIGNIFICANCE}

As a herpesvirus, the life cycle of Kaposi's sarcoma-associated herpesvirus (KSHV) consists of two phases, latent and lytic (Renne et al., 1996; Miller et al., 1997). In immunocompetent individuals, KSHV establishes latent infection following an acute infection. Latent infection is characterized by expression of only a few of viral genes (termed latent genes) and no production of infectious virions. Multiple copies of viral genome are maintained as extrachromosomal episomes and are replicated in synchrony with cell division (Ballestas et al., 1999). When latency is disrupted, KSHV switches to a lytic life cycle, where the virus expresses most or all of its genes, viral DNA is amplified by the rolling cycle mechanism that generates long head-to-tail concatemers of viral genomes, and progeny virions are assembled and released from the cells (Renne et al., 1996; Gradoville et al., 2000; Lin et al., 2003).

What is the biological significance for a virus to have both latency and lytic life cycles? KSHV has coevolved with its mammalian hosts for millions of years (McGeoch and Davison, 1999) and development of lifetime latency in host is an outcome of the compromises from both sides. It is not in the evolutionary interest of viruses to kill or seriously hurt their residence because viruses need hosts to be healthy in order to support their survival and reproduction. On the other hand, host immune surveillance is competent enough to keep viruses from being harmful (Bhatt and Damania, 2013). T cell responses to KSHV have been studied mostly in Kaposi's sarcoma (KS) patients and asymptomatic KSHV carriers and such responses to several lytic and latent viral proteins have been detected and demonstrated to be functionally cytotoxic in vitro. Both CD4 and CD8 T cell responses have been detected. For example, CD8 T cell responses were found against a broad spectrum of immediate-early (IE), delayed-early (DE), and late gene products like ORF8, ORF22, ORF25, ORF26, and ORF57 (Wang et al., 2001; Lambert et al., 2006; Lepone et al., 2010) and CD4 responses to ORF57, ORF73, K12, K15 and K8.1 (Guihot et al., 2006; Robey et al., 2010). The most compelling evidence for the role of $\mathrm{T}$ cell immunity in controlling KSHV reactivation came from Myoung and Ganem (2011) who showed that when mixed culture of human tonsillar B cells and activated T cells were exposed to KSHV, latent infection could be established in B cells with little spontaneous virus production. However, depletion of $\mathrm{T}$ cells from the mix or treating the mixed culture with immune suppressants greatly enhanced spontaneous lytic production, demonstrating the importance of $\mathrm{T}$ cell immunity in containing KSHV reactivation.

In parallel to T cell suppression of KSHV reactivation, KSHV pathogenicity, such as KS development, is also under the control of $\mathrm{T}$ cell immunity. Low CD4 $\mathrm{T}$ cell counts in HIV-infected individuals are directly associated with the incidence of KS, which can spontaneously regress with immune reconstitution through highly active antiretroviral therapy (HAART) (Lebbe et al., 1998; Jones et al., 2000; Cattelan et al., 2001; Pellet et al., 2001; Wilkinson et al., 2002; Casper et al., 2004a; Mocroft et al., 2004).

Owing to the effective immune surveillance, especially $\mathrm{T}$ cell immunity, to $\mathrm{KSHV}$, establishment of latency in an infected individual is a wise strategy for the viruses to escape immune surveillance and maintain persistent infection. However, reactivation from latency and switch to lytic viral replication cycle is necessary for the viruses to propagate in the individual and spread to other individuals.

\section{INITIATION OF KSHV REACTIVATION AND SWITCH FROM LATENT TO LYTIC REPLICATION}

The balance between KSHV latent and lytic viral life cycle is under the control of sophisticated mechanisms that make it possible for a herpesvirus to get in and out of its host efficiently and freely. In addition to serving for viral propagation, the KSHV lytic life cycle also plays important roles for viral pathogenicity. In KS lesions, most spindle cells are latently infected with KSHV, but a small percentage of these cells undergo spontaneous lytic replication (Zhong et al., 1996; Staskus et al., 1997; Sun et al., 1999). Viral propagation and release of nascent KSHV particles is crucial to sustaining the population of latently infected cells that otherwise would be quickly lost by segregation of latent viral episomes as spindle cells divide (Grundhoff and Ganem, 2004). Thus, KSHV lytic replication and constant infection to fresh cells are crucial for viral tumorigenesis.

\section{Cellular Factors and Signaling}

The reactivation of KSHV can be initiated artificially by treating latently infected cells with certain chemicals such as 12-OTetradecanoyl-phorbol-13-acetate (TPA) and sodium butyrate (Miller et al., 1997). These chemicals have been used as very 
handy tools in the research on the biology of KSHV lytic life cycle. Although they are artificial inducers, they inform that host cell signal transduction and epigenetic regulation are the mechanisms underlying the switch of the virus between latency and lytic replication. TPA is one of the most potent inducers of lytic KSHV reactivation, which is found to trigger $\mathrm{KSHV}$ reactivation cascade through activating protein kinase $\mathrm{C}$ (PKC) delta isoform, leading to stimulation of the mitogenactivated protein kinase (MAPK)/extracellular signal-regulated kinase (ERK) pathway. As a consequence of the activation of the pathway, c-Fos is accumulated and c-Jun is phosphorylated, leading to the formation of an active AP- 1 complex and activation of RTA gene and the lytic cascade of KSHV (Cohen et al., 2006). Yu et al. (2007) attempted to systematically elucidate the cellular signaling that could be responsible for activating KSHV lytic cycle. They screened the effect of ectopic expression of 26,000 individual cDNA clones on RTA-dependent transcription activity in a primary effusion lymphoma (PEL) cell line latently infected with KSHV and identified a signaling molecule $\mathrm{v}-\mathrm{Ki}$ ras2 that promoted RTA transcription activity by148.1-fold. $\mathrm{v}$-Ki-ras2 activates RTA and the downstream genes including PAN, kaposin, ORF57, and vIL-6. This study demonstrated that the Raf/MEK/ERK/Ets-1 pathway mediates Ras-induced activation of RTA. This pathway also mediates TPA-induced KSHV reactivation ( $\mathrm{Yu}$ et al., 2007). The TPA and Ras-initiated signal transduction pathways that lead to activation of RTA gene is illustrated in Figure 1.

Ionomycin, a calcium ionophore, was found to be able to induce reactivation of KSHV from latency in PEL cells, suggesting that intracellular immobilization of calcium is able to trigger KSHV lytic replication (Chang et al., 2000). Calciummediated virus reactivation can be blocked by specific inhibitors of calcineurin-dependent signal transduction (cyclosporine, FK506). Furthermore, retroviral transduction with plasmid encoding VIVIT, a peptide specifically blocking calcineurinNFAT interactions, inhibited calcium-dependent KSHV reactivation (Zoeteweij et al., 2001). Taken together, calcineurindependent signaling cascade induces calcium-dependent KSHV replication (reviewed in Feske et al., 2003) (Figure 1).

The autonomic nervous system (ANS) may also play a role in KSHV reactivation. It has been known that high levels of ANS activity accelerate the onset of AIDS-defining conditions during human immunodeficiency virus type 1 infection (Cole et al., 2003). Epinephrine and norepinephrine at physiological concentrations can induce lytic replication of KSHV in latently infected lymphoid cells via $\beta$-adrenergic activation of the cellular protein kinase A (PKA) signaling pathway. PKA increases expression of RTA and post-translational enhancement of the trans-activating capacity of RTA (Chang M. et al., 2005). Along with the above mentioned lytic activators, several other cellular factors, such as XBP-1, CBP, the SWI/SNF chromatin remodeling complex, the TRAP/Mediator complex, RBP-Jא, human Notch intracellular domain, and HMGB1, have been shown to promote $\mathrm{KSHV}$ reactivation and/or lytic gene expression (Liang et al., 2002; Gwack et al., 2003a; Wilson et al., 2007; Yu et al., 2007; Harrison and Whitehouse, 2008; Xie et al., 2008). On the other hand, some cellular factors, such as hKFC, PARP-1, Oct-2, KAP-1, and Heyl were found to inhibit RTA activation and viral lytic replication and may play roles in the maintenance of viral latency (Gwack et al., 2003b; Chang et al., 2009; Di Bartolo et al., 2009; Gould et al., 2009; Cheong et al., 2015).

The early finding that inhibition of the NF- $\kappa$ B pathway in KSHV latently infected PEL cells led to lytic gene expression and viral reactivation (Brown et al., 2003) implied a pivotal role of the NF- $\kappa$ B pathway in regulation latency and lytic replication. In B lymphocytes and endothelial cells, KSHV infection causes transient activation of NF- $\kappa \mathrm{B}$ and sustained NF- $\kappa \mathrm{B}$ activity, which is a feature of viral latency, requires expression of latent gene vFLIP (Chaudhary et al., 1999; Guasparri et al., 2004). By activating NF- $\kappa \mathrm{B}$ pathway, vFLIP inhibits the expression of lytic genes through NF- $\kappa \mathrm{B}$-mediated suppression of the AP-1 pathway as well as blocking RTA transactivation in lytic gene promoters by antagonizing the RBP-JK coactivator (Ye et al., 2008; Izumiya et al., 2009). NF-кB is down-regulated when KSHV reactivation occurs. It was reported that lytic proteins K1, K9, and K14 inhibit NF-кB pathway (Samaniego et al., 2000; Konrad et al., 2009). Interestingly, once KSHV lytic replication takes place, some lytic proteins up-regulate NF- $\kappa \mathrm{B}$, probably for that the new increase of NF- $\kappa \mathrm{B}$ is required for anti-apoptotic activities to secure the completion of viral lytic replication (Cannon and Cesarman, 2004; Martin et al., 2008).

Efficient induction of KSHV reactivation by sodium butyrate (Miller et al., 1997) and DNA demethylation agent $5^{\prime}$-azacytidine (Chen et al., 2001) suggests that epigenetic regulation plays an important role in the switch of the virus between latent and lytic replication. Sodium butyrate is known to be an inhibitor of histone deacetylation (HDAC) activity and treatment of cells results in histone hyperacetylation (Candido et al., 1978). Sodium butyrate activates the RTA promoter by induction of histone $\mathrm{H} 3$ and $\mathrm{H} 4$ hyperacetylation that rapidly associates chromosome remodeling protein Inil/Snf5 with the RTA promoter (Lu et al., 2003). The recent advances in the epigenetic regulation of KSHV reactivation will be discussed as a specific topic below.

\section{Viral Co-infection}

There are many instances where KSHV reactivation can be induced by co-infection with other viruses, such as HIV, herpes simplex virus type 1 (HSV-1), HSV-2, human cytomegalovirus (HCMV), human herpesvirus-6 (HHV-6), HHV-7, and papillomavirus (Vieira et al., 2001; Tang et al., 2012). One of the mechanisms for other viral co-infection to trigger $\mathrm{KSHV}$ reactivation is the secretion of inflammatory cytokines, such as oncostatin M (OSM), hepatocyte growth factor (HGF), interferon- $\gamma$ (IFN- $\gamma)$, and Toll-like receptors 7 and 8 (TLR7/8) (Mercader et al., 2000; Gregory et al., 2009) triggered by coinfected viruses. In contrast, KSHV lytic replication is inhibited by co-infection with Epstein-Barr virus (EBV) (Jiang et al., 2008).

It has been long suspected that HIV infection has great impacts on KSHV replication and pathogenicity. The overall risk of KS in AIDS patients was estimated to be more than 20,000-times greater than that of the general population and 300times that of other immunosuppressed patients. AIDS-related immunosuppression appears to be a key facet to KS development and progression. HIV infection causes decreased counts of 


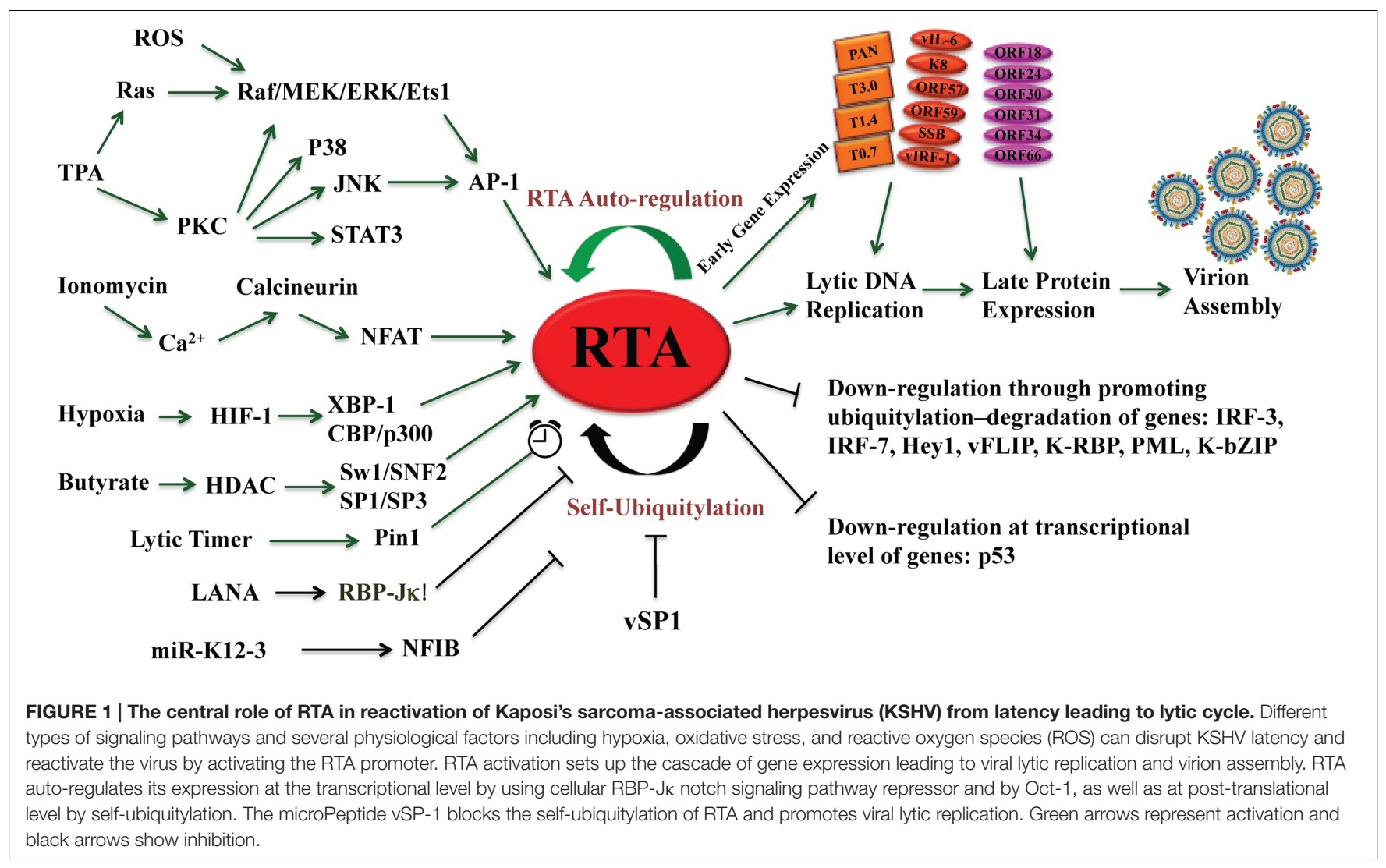

$\mathrm{CD} 4+$ cells and expansion of $\mathrm{CD} 14^{++} \mathrm{CD} 16^{+}$monocytes. The unbalanced population of CD4+ cells and chronic inflammation caused by HIV leads to KSHV lytic reactivation. KSHV DNA increases in KSHV-positive patients as CD4+ count drops (Whitby et al., 1995; Martin et al., 1998; Min and Katzenstein, 1999; Keller et al., 2001; McCune, 2001; Tedeschi et al., 2001; Lukac and Yuan, 2007). T-cell proliferative responses and neutralizing antibodies to $\mathrm{KSHV}$ are also lower among these patients (Strickler et al., 1999; Kimball et al., 2004). The advent of HAART has resulted in recent declines of KS in the USA and many other populations (Jones et al., 2000; Mocroft et al., 2004; Iroezindu, 2016). HAART therapy leads to restoration of CD4+ cells (Lebbe et al., 1998; Jones et al., 2000; Cattelan et al., 2001; Pellet et al., 2001; Tam et al., 2002; Wilkinson et al., 2002; Nasti et al., 2003; Casper et al., 2004b; Mocroft et al., 2004), CD8+ cells (Wilkinson et al., 2002; Bourboulia et al., 2004), and NK cells (Sirianni et al., 2002). During recovery of CD4+ cells, some patients show KSHV inflammatory disease known as immune reconstitution inflammatory syndrome-KS (IRIS-KS) (Bower et al., 2005). KSHV inflammatory cytokine syndrome (KICS) is another complication of KSHV caused mainly by high levels of viral interleukin-6 (vIL6) or human IL-6 (hIL-6) and high viral load has been found in both HIV-infected and nonHIV-infected KSHV patients (Uldrick et al., 2010).

Immunosuppression clearly has an important role in $\mathrm{KS}$ replication and $\mathrm{KS}$ development, but cannot explain why the incidence of KS is highest in patients with AIDS as compare to non-AIDS immunosuppressed individuals. Onset of KS in HIV-positive individuals often occurs before appearance of severe immunosuppression. Even during HARRT therapy, rapid regression of KS was observed in patients under HARRT therapy before the complete restoration of the immune system (Zhu et al., 2014). In order to answer these questions, studies have been carried out on the direct action of HIV-1 on KSHV replication and $\mathrm{KS}$ pathogenicity. In a KSHV-infected primary effusion lymphoma (BC-3) cell line, infection of HIV-1 led to reactivation of the KSHV genome (Merat et al., 2002). HIV-1 was found to induce KSHV lytic replication through the activation of RTA in bystander cells by secretion of soluble factor(s) (Varthakavi et al., 1999, 2002). HIV-1 does not infect endothelial cells but it can send signaling molecules that penetrate the endothelial cells. For example, HIV-1 Tat acts as a growth factor for KSderived endothelial cells (Guo et al., 2004; Zhu et al., 2014). It has been demonstrated that Tat triggers $\mathrm{KSHV}$ reactivation from latency (Harrington et al., 1997; Zeng et al., 2007) and also accelerates tumor progression induced by KSHV-encoded oncoproteins such as $\mathrm{G}$ protein-coupled receptor and kaposin A. In addition to Tat, accessory negative factor (Nef) is another early $\mathrm{HIV}$-1-encoded regulatory protein that is an enforcing factor in the pathogenesis of HIV/AIDS and it can penetrate KSHV vIL-6expressing endothelial cells. Both Nef and vIL-6 are internalized and in endothelial and fibroblast cells Nef synergizes with vIL6 to promote vascular tube formation and cell proliferation. It was also shown that Nef can promote angiogenesis and vascular 
tube formation by activating the AKT pathway in a chicken chorioallantoic membrane (CAM) model, as well as in nude mice (Zhu et al., 2014).

Not only does HIV increases the risk of KS but co-infection of KSHV also increase the replication of HIV, moreover the entry of HIV-1 to non-infected cells. KSHV RTA, LANA, ORF45, vFLIP, ORF57 modulate the activity of the long terminal repeat region (LTR) of HIV-1 through their cooperative action with HIV-1 Tat or NF-кB signaling pathway (Caselli et al., 2001; Huang et al., 2001; Hyun et al., 2001; Sun et al., 2005; Thakker and Verma, 2016). ORF45 stimulates the transcriptional activation of HIV1 LTR via RSK2 signaling (Karijolich et al., 2014). LANA can inhibit HIV-1-LTR via negative effect on NF-kB signaling or by induction of Staf-50 transcription factor, an inhibitor of HIV-1LTR (Renne et al., 2001). These data show that the co-infection of KSHV can enhance or inhibit HIV-1, or vice-versa.

\section{Hypoxia}

Clinical observation that KS tumors often appear on the extremities of the body such as feet and arm, suggests that hypoxia may contribute to KSHV reactivation and tumorigenesis. This notion has been supported by the experimental results that hypoxia induces KSHV lytic replication in PEL cells (Davis et al., 2001). These studies found that hypoxia induced accumulation of hypoxia inducible factors (HIF) $1 / 2$. HIF-1 is a nuclear protein that activates gene transcription specifically in response to reduced cellular $\mathrm{O}_{2}$ concentration. HIF-1 is a heterodimer composed of HIF- $1 \alpha$ and HIF-1 $\beta$ subunits, members of the basic helix-loop-helix superfamily of transcription factors. HIF1 activity is regulated primarily by oxygen-dependent modulation of steady-state HIF- $1 \alpha$ or HIF- $2 \alpha$ protein levels (Semenza, 1998). In the KSHV genome, promoters of RTA and ORF3437 lytic genes cluster contain functional hypoxia response elements (HREs) (Cai et al., 2006; Haque et al., 2006). The RTA promoter mainly responds to HIF- $2 \alpha$ while the ORF34 promoter responds to both HIF- $1 \alpha$ and HIF- $2 \alpha$, resulting in lytic reactivation of KSHV. Hypoxia/HIF-mediated KSHV lytic replication is regulated by both viral and cellular proteins. LANA is found to cooperate with HIF- $1 \alpha$ to activate the RTA promoter. LANA also recruits chromatin remodeler KAP1 to the RTA promoter to block HIF-1 $\alpha$-mediated lytic replication (Cai et al., 2006, 2013). Dissociation of KAP1 from the LANARBP-JK-HIF1 $\alpha$ complex on the promoter under hypoxic stress or knock down of KAP1 expression enhances viral reactivation (Cai et al., 2013; Zhang et al., 2014). The X-box binding protein 1 (XBP1) synergizes with HIF-1 $\alpha$ to transacitvate the RTA promoter (Ramirez et al., 2004; Griffin et al., 2009). In addition, HIFs are able to promote aerobic glycolysis to obtain energy (ATP) and biosynthetic intermediates to sustain the growth of cancer cells, which is known as Warburg effect. Such phenomena have been found in KSHV-infected endothelial cells where KSHV up-regulates HIF-1 metabolic effector, pyruvate kinase 2 (PKM2), to maintain aerobic glycolysis in infected cells. Furthermore, as a coactivator of HIF-1, PKM2 positively regulates KS angiogenesis phenotype and increases the expression of HIF1-dependent angiogenic factors including VEGF (Tao et al., 2015).

\section{Oxidative Stress}

Molecules containing oxygen with unpaired electrons are known as reactive oxygen species (ROS). These unpaired electrons of oxygen can react to form partially reduced, highly reactive species, for example, superoxide $\left(\mathrm{O}_{2}\right)$, hydrogen peroxide $\left(\mathrm{H}_{2} \mathrm{O}_{2}\right)$, hydroxyl radicals, and peroxynitrites (Fruehauf and Meyskens, 2007). ROS originate from various cellular enzyme systems, such as the mitochondrial electron transport chain, the NADPH oxidase complex, xanthine oxidase, lipoxygenase, cyclooxygenase, and peroxisomes. Increasing evidence suggests the role of oxidative, nitritive stress, and ROS in KSHV reactivation in KS patients (Gil et al., 2003; Mallery et al., 2004; Ye et al., 2011). During infections and inflammatory responses, host phagocytes produce and release excessive amounts of $\mathrm{H}_{2} \mathrm{O}_{2}$, which induces expression of RTA, ORF57, ORF59, K8, ORF65 in a dose-dependent manner in BCBL1 and human umbilical vein endothelial cells (HUVEC) latently infected with $\mathrm{KSHV}$ (Ye et al., 2011). $\mathrm{H}_{2} \mathrm{O}_{2}$ induction of KSHV reactivation depends on the activation of MAPK ERK1/2, JNK, and p38 pathways (Li et al., 2011; Ye et al., 2011) (Figure 1). Cells express multiple antioxidant enzymes such as catalase and glutathione peroxidase to remove $\mathrm{H}_{2} \mathrm{O}_{2}$. The cells with catalase knock down by siRNA increased the expression of KSHV lytic transcripts. Disruption of the intracellular redox balance through depletion of the antioxidant glutathione or inhibition of the antioxidant enzyme catalase also induces KSHV reactivation, confirming that hydrogen peroxide induces reactivation.

\section{MECHANISMS THAT REGULATE THE SWITCH OF KSHV BETWEEN LATENCY AND LYTIC REPLICATION}

\section{Kinetic Classification of KSHV Lytic Genes}

Like all herpesviruses, KSHV lytic replication proceeds as viral lytic genes are induced in a cascade fashion. The kinetics of KSHV gene expression has been studied in both tissue culture and clinical samples. Miller's group classified KSHV genes in accordance to their response to treatment of cycloheximide (CHX) - a protein synthesis inhibitor and phosphonoacetic acid (PAA) - an inhibitor of DNA polymerase (Sun et al., 1999). The genes that constitutively express in both latent and lytic life cycles are designated as latent genes. The genes that express only after induction of cells with chemical inducers such as TPA or butyrate are lytic genes. Among them, the genes that can be induced by TPA or butyrate in the presence of CHX are termed IE genes, as their induced expression does not require de novo protein synthesis. DE genes express after IE gene products are synthesized but prior to viral DNA synthesis. Their expression is blocked in the presence of CHX but not affected by inhibition of viral DNA replication by PAA. Late (L) gene expression is coupled with the viral lytic replication and can be only detected after viral DNA replication initiation. In accordance with these criteria, a class of genes including RTA, K8, and ORF45 are designated IE genes (Zhu et al., 
1999). DE genes, in general, encode enzymes and regulatory proteins required for supporting viral DNA replication and creating favorable cellular environment for success of lytic viral replication. The majority of the genes for viral structural proteins, including capsid, tegument, and glycoproteins are late genes with exceptions, that is, if they carry out other functions in other dynamical phases of viral life cycle (Saveliev et al., 2002). How the expression of KSHV genes in different kinetic categories is regulated in coordination is the central question on KSHV switch between latent and lytic cycle and proceeding of lytic replication.

\section{Immediate-Early Gene Product RTA Is the Major Viral Lytic Switch Protein}

Among KSHV IE gene products, ORF50-encoded RTA is a key regulator for the switch between latent and lytic viral life cycle. RTA expression is necessary and sufficient for KSHV reactivation. Ectopic expression of RTA in latently infected B-lymphocytes results in completion of the cascade leading to KSHV lytic replication (Lukac et al., 1998; Sun et al., 1998). RTA is conserved among all members of gamma-herpesvirus family such as EBV, rhesus rhadinovirus (RRV), herpesvirus saimiri (HVS), murine herpesvirus 68 (MHV-68), bovine herpesvirus 4 , and equine herpesvirus 2, but only the RTAs from gamma2-herpesviruses (KSHV, HVS, and MHV-68) acts as a lytic replication activator (Sun et al., 1998; Wu et al., 2000; Goodwin et al., 2001). RTA is a transcription activator with unique features: its DNA binding region does not contain any wellcharacterized DNA binding motifs and the overall protein shows no homology to any known cellular transcriptional activators. Therefore, RTA could be an attractive target for antiviral therapy.

RTA is a 691 amino acid protein (Figure 2). As a nuclear protein, it has two arginine- and lysine-rich nuclear localization signals, one at the N-terminus in aa 1-13 and the other near its C-terminus in aa 514-528 (West and Wood, 2003; Bu et al., 2008). The DNA binding and dimerization domains are located at the aa 1-530 (Lukac et al., 2001; Chang and Miller, 2004). The transactivation domain has been defined at the aa 486-691, which is highly acidic and contains numerous charged amino acids (Lukac et al., 1999; Seaman et al., 1999) (Figure 2). This region contains four repeated units of a highly hydrophobic domain, known as activation domains 1-4 (AD1-AD4), with sequence homology to other transcriptional factors such as VP16 domain A (Lukac et al., 1999). Deletion of acidic activation domain results in dominant negative of RTA and inhibits viral lytic reactivation. RTA also has prolinerich region, serine/threonine-rich region, cysteine/histidine-rich region, leucine heptapeptide repeat domain, and 4-hydrophobicacidic repeat regions (486-691) (Guito and Lukac, 2015). A region (aa 520-535) centered with a basic motif (KKRK) regulates abundance of RTA. This region (aa 520-535), together with a downstream sequence (aa 590-650), constitutes the protein abundance response signal (PARS). Mutants or deletion of these motifs greatly enhanced the abundance of RTA in cells as well as DNA binding activity. Interestingly the PARS mutations inhibit RTA transactivation activity, suggesting that this motif is required for controlling RTA abundance, DNA binding and transactivation activity (Chang and Miller, 2004; Chang et al., 2008). Given that the PARS mutations gave rise to an RTA variant with faster electrophoretic mobility (form B of RTA), PARS-mediated regulations (abundance, DNA binding and transactivation) may involve post-translational modification (PTM).

RTA activates a number of viral promoters by different mechanisms as follows: (1) RTA binds to DNA of three promoters for PAN RNA, ori-Lyt-associated RNA (T1.4) and T0.7, directly and tightly by recognizing the RTA responsive elements (RREs). These three RREs share a 16-bp core sequence and designated type I RREs (Lukac et al., 2001; Song et al., 2002; Wang et al., 2003a); (2) RTA activates the promoters of ORF57 and K8 (delayed-early promoter) by binding to type II RREs, which exhibit varying binding affinity for RTA but required cooperative interaction with various cellular factors (Liang and Ganem, 2003; Wang et al., 2003a,b; Wang S.E. et al., 2004; Wen et al., 2009). Transactivation of ORF57 and K8 genes by RTA requires a direct interaction with RBP-Jк and RTA may bind to the type II RREs (contain RBP-J火 binding sites) by piggybacking on to the cellular protein (Liang et al., 2002; Wang and Yuan, 2007). In fact, RBP-J $\kappa$ binding has been identified to at least 99 sites within the KSHV genome and involves as many as 34 RTAactivated viral genes, which suggests the potential for an RTARBP-J $\kappa$ complex to induce the entire lytic cascade (Guito and Lukac, 2015). KSHV may regulate cellular genes using RTA-RBPJк complex as a ChIP-seq analysis shows 3,846 Notch1 binding sites and 2112 of RBP-JК binding sites in human T-lymphoblastic leukemia cell lines (Wang et al., 2011). For example, RTA is able to activate cellular genes for surface protein CD21 and CD23 through interaction with RBP-Jк (Chang H. et al., 2005). RTA was also found to activate its target genes in combination with other cellular transcription factors, like Octamer-1, C/EBP $\alpha, \mathrm{C}-J u n$, SP1, and STAT3 (Sakakibara et al., 2001; Wang et al., 2003a; Wang S.E. et al., 2004; Carroll et al., 2006, 2007; King et al., 2015); (3) RTA has been also found to promote gene expression through the degradation of transcriptional repressors. RTA exhibits an ubiquitin E3 ligase activity that directs proteasome-mediated degradation of lytic gene expression repressor including Hey1 and LANA (Yang et al., 2008; Gould et al., 2009; reviewed in Guito and Lukac, 2012). Through these various mechanisms, RTA efficiently activates gene expression cascade leading to completion of viral lytic replication. These all have been illustrated in Figure 1.

\section{Regulation of RTA Function by LANA}

As RTA is an important regulator controlling the switch between latency and lytic viral replication and determining the fates of both virus and host, it has to be under control with maximum security. RTA is the first viral gene to be expressed following de novo infection. Expressed RTA immediately activates LANA gene, thereafter initiating the establishment of latency (Lan et al., 2005b). LANA expression in turn down-regulates RTA expression (Lan et al., 2004). In the cell with a LANA-null recombinant mutant $\mathrm{KSHV}$, there is tremendously increased 


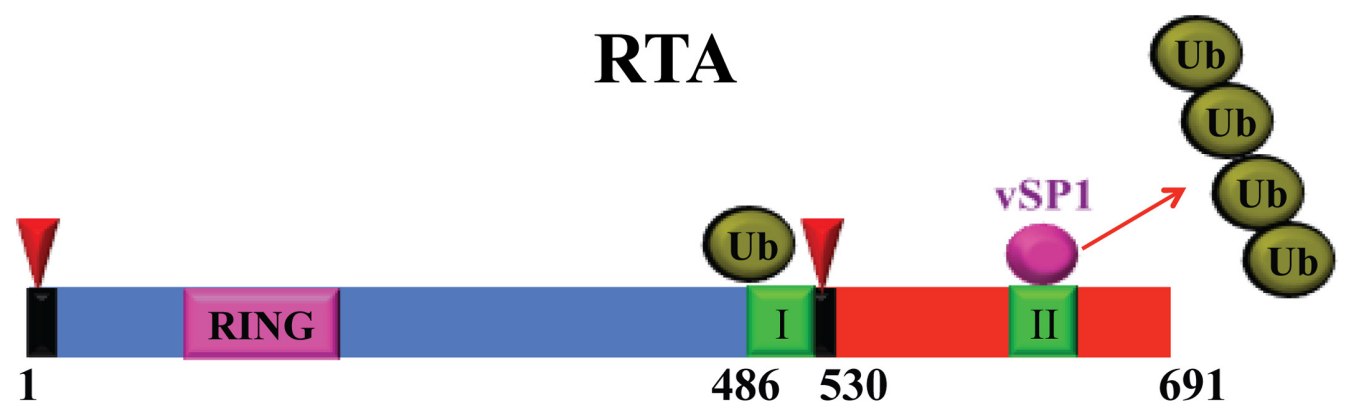

NLS I: 1-13, NLS II: 514-528 (shown by red arrows)

DNA-binding and Dimerization Domain: 1-530

Ring Finger-like Domain, E3 Ligase: 118-207

Protein Abundance Response Signal (PARS) I: 490-535, PARS II: 590-650

Transactivation Domain: 486-691

FIGURE 2 | Schematic representation of RTA and functional domains. The RTA nuclear localization signals (NLS), RING finger-like domain, protein abundant regulatory signal (PARS), and transactivation domain are shown with color codes as indicated. RTA undergoes auto-ubiquitylation by the E3 ligase activity of the ring finger-like domain for a self-control of its abundance. A microPeptide (VSP1) interacts with PARS II domain and lifts the abundance restriction by blocking RTA self-ubiquitylation.

expression of lytic genes including RTA, vIL-6, ORF57, ORF59, and K8.1, indicating LANA represses expression of RTA as well as other RTA-responsive genes (Lu et al., 2006; Li et al., 2008). LANA interacts with the RTA promoter and inhibits RTA gene expression. LANA-mediated repression of RTA promoter activity depends on RBP-J $\kappa$ binding sites. LANA recruits RBPJ $\kappa$ protein to the RTA promoter and blocks the self-activation of the promoter by competing with RTA for RBP-Jк-binding (Lan et al., 2005a). Therefore, the switch of KSHV between latency and lytic cycle is controlled by the interplay between LANA and RTA proteins in infected cells.

\section{Regulation of RTA Abundance by Self-Ubiquitylation and microPeptides}

Another level of regulation is on the protein abundance of RTA. Miller et al. (1997) reported that the level of RTA in cells is controlled by the regulatory domains called PARS, which consists of two components, namely PARS I (aa 490-535) and PARS II (aa 590-650) (Chang et al., 2008). Mutation or deletion of either component results in abundant expression of RTA protein. The $\mathrm{N}$-terminus of RTA contains a RING finger-like domain, which possesses E3 ligase activity that ubiquitylates and degrades some viral and cellular targets, including K-bZIP, PML, IRF-7, and K-RBP (Yu et al., 2005; Yang et al., 2008; Izumiya et al., 2013; Ehrlich et al., 2014). Our preliminary data showed that the E3 domain of RTA is also capable of self-ubiquitylating RTA itself possibly at the PARS domain. Therefore, RTA utilizes the selfubiquitylation mechanism to maintain RTA at a relatively low level in order to prevent the virus from unwanted reactivation.
Interestingly, KSHV has also developed a mechanism to counteract the self-ubiquitylation-mediated abundance control using a virally encoded microPeptide. When KSHV switches to lytic life cycle, elevated RTA promotes the transcription from the strand opposite of the ORF50 DNA that gives rise to a previously annotated non-coding RNA, termed T3.0 (Saveliev et al., 2002). Originally, it was found that T3.0 RNA could relieve the PARSmediated RTA abundance restraint and increase the RTA level in cells. Further investigation indicated that the up-regulation of RTA expression is not mediated by the non-coding RNA, but by a microPeptide translated from T3.0 RNA. Although T3.0 was annotated as a non-coding RNA, T3.0 transcript carries a series of small open reading frames (sORF). Ganem's group reported that the T3.0 RNA is associated with ribosomes and some of the sORFs in T3.0 RNA do have the potential to make small peptides ( $\mathrm{Xu}$ and Ganem, 2010). The translation of these sORFs in cells was confirmed and two small peptides (vSP-1 and vSP-2) were identified that are translated from potential sORFs encompassing the nucleotides 74356-74035 and 74029-73912 within T3.0 RNA. These two small peptides, 48- and 27-aa in length, respectively, are designated as microPeptides (vSP-1 and vSP-2). Two lines of experiment were carried out to determine if these two microPeptides are capable of regulating RTA. First, the initiation codons of vSP-1 and vSP-2 were altered from AUG to AAG. When the mutants were introduced into cells along with an RTA expression vector, the mutation at vSP-1 initiation codon abolished the RTA enhancement activity of T3.0, while the mutant bearing the mutation at the vSP-2 initial codon retained the activity comparable to wild-type T3.0. Second, the ectopic 
expression of vSP-1 led to the increase of RTA abundance similar to that of T3.0 RNA. These results strongly suggested that T3.0 could regulate RTA expression through a microPeptide (Jaber and Yuan, 2013).

The microPeptide vSP-1 physically interacts with RTA at the PARS II domain. The interaction blocks the self-ubiquitylation of RTA by the internal E3 ligase located at the RING domain (Jaber and Yuan, 2013) (Figure 2). Thus the balance of RTA self-ubiquitylation and the microPeptide action provide a precise control of RTA abundance and activity.

\section{Role of Pin1 Isomerase in Regulation of KSHV Lytic Reactivation}

Most of amino acids exist in trans-form in proteins except proline which is known as imino acid as it possesses both cis- and trans-isoforms. This cis/trans-isomerization plays an important role in protein folding. Peptidyl-prolyl cis/trans isomerase Pin1 is an enzyme catalyzing prolyl hydroxylation and prolyl isomerization (Wedemeyer et al., 2002). Pin1 targets phosphoserine or phosphothreonine-proline motifs and convert them from trans- to cis-form, a post-phosphorylation event. The locking mechanism of Pin 1 controls the timing and amplitude of a specific process such as protein folding or G1/S check point (Lu et al., 2007). Dysregulation of Pin-1 has been associated with cancers and Alzheimer's disease (reviewed in Guito and Lukac, 2015).

In RTA, prolines constitute $17 \%$ conserved amino acids among members of the gamma-Herpesviridae subfamily and these prolines are present in critical domains like oligomerization, DNA binding, and RBP-J $\kappa$ binding domain, suggesting an important role of these prolines in RTA function (Bu et al., 2007; Guito et al., 2014). RTA contains 15 potential binding and regulatory motifs for Pin 1 and RTA indeed physically interacts with Pin1. RTA transactivation is enhanced by Pin 1 at two delayed-early viral promoters for PAN RNA and ORF57. However, ectopic expression of Pin 1 inhibits late gene expression and production of infectious virus (Guito et al., 2014; Guito and Lukac, 2015). These data suggest that Pin1 may act as KSHV lytic cycle timer that controls the balance between viral lytic replication and host cell lysis through regulating RTA expression and downstream activity.

\section{EPIGENETIC REGULATION OF KSHV REACTIVATION}

\section{Chromosome Conformation and Chromatin Remodeling}

First implication that KSHV is epigenetically controlled comes from its activation by histone deacetylase (HDAC) inhibitors sodium butyrate or trichostatin A, and DNA methyltransferase inhibitor 5-Azacytidine (5-AzaC) (Renne et al., 1996; Lu et al., 2003). These chemicals have global effects on chromatin modeling and gene expression. Epigenetic alterations involve many enzymes for histone modifications and chromatin modeling. Histone modification enzymes can be classified into three categories: (1) writers: histone acetyltransferases (HATs) and histone methyltransferases (HMTs); (2) erasers: HDACs and histone lysine demethylases (KDMs and Jumonji families); and (3) readers: proteins that recognize these histone modifications. The KSHV genome is histone-free in virions but quickly adopts a highly organized chromatin structure following de novo infection. The chromatinated KSHV genome is distinctively enriched with the activating (acetylated H3 and $\mathrm{H} 3 \mathrm{~K} 4 \mathrm{me} 3$ ) and repressive (H3K9me3 and $\mathrm{H} 3 \mathrm{~K} 27 \mathrm{me} 3$ ) histone modifications. During latency, the latency-associated gene cluster is associated with activating histone marks accompanied by transcriptionally active RNA polymerase II binding. The promoters of RTA and some DE genes have bivalent chromatin marks (enriched with both activating $\mathrm{AcH} 3$, $\mathrm{H} 3 \mathrm{~K} 4 \mathrm{me} 3$ and repressing $\mathrm{H} 3 \mathrm{~K} 27 \mathrm{me} 3$ histone modifications), whereas the late genes are in repressive $\mathrm{H} 3 \mathrm{~K} 9 \mathrm{me} 3$ - and H3K27me3-marked heterochromatin (Gunther and Grundhoff, 2010; Toth et al., 2010; Uppal et al., 2015). Polycomb repressive complex 2 (PRC2), composed of subunits EZH2, SUZ12, EED, and RbaAp48/46 (Simon and Kingston, 2009), colocalizes with the H3K27me3 mark on the entire KSHV genome and EZH2 catalyzes the methylation of $\mathrm{H} 3 \mathrm{~K} 27$ during latency (Toth et al., 2010). In addition, JMJD2A, a H3K9me3 demethylase, is associated with the latent region and prevents the methylation of H3K9 (Chang et al., 2011). Along with PRC2 complex, PRC1 complex that mono-ubiquitinates lysine 119 of $\mathrm{H} 2 \mathrm{~A}$ (H2AK119ub) and represses transcription has been also detected on the RTA promoter (Toth et al., 2013). Once viral lytic cycle is induced, EZH2 of PRC2 dissociates from the genomic regions of IE and DE genes concurrent with decreasing $\mathrm{H} 3 \mathrm{~K} 27 \mathrm{me} 3$ and increasing acH3 and $\mathrm{H} 3 \mathrm{~K} 4 \mathrm{me} 3$ with subsequent lytic gene expression (Figure 3). This shift allows RTA to recruit cellular transcriptional cofactors such as TBP, CBP, Brg1, BAF170, TRAP220, and TRAP100, leading to optimal RTA production and activation of entire viral lytic program (Figure 3) (Gunther and Grundhoff, 2010; Toth et al., 2010).

Interestingly, KSHV non-coding RNA PAN was found to play a critical role in the changes in the histone modification that leads to shift of the KSHV IE and DE gene region to activating chromatin. A PAN-null recombinant mutant KSHV fails to express RTA and to enter lytic cycle. PAN RNA, serving as a guide RNA, recruits histone demethylases UTX and JMJD3 to the IE and $\mathrm{DE}$ gene location to remove the repressive marks H3K27me3 in the RTA promoter. PAN RNA also delivers H3K4me3 methyltransferase MLL2 (KMT2D) to the region to add the reactivating marks (Rossetto and Pari, 2012, 2014) (Figure 3).

The chromatin remodeling is region specific with certain histone marks enriched only on specific viral genomic regions. Increasing data suggest that chromosome conformation may determine the epigenetic patterning of a viral genome. The chromatin organizing factor CTCF has been implicated in the control latent and lytic gene expression of KSHV and other herpesviruses. CTCF can prevent the spread of activating and repressive chromatin from one regulatory domain to another by acting as an insulator (reviewed in Lieberman, 2013). In 


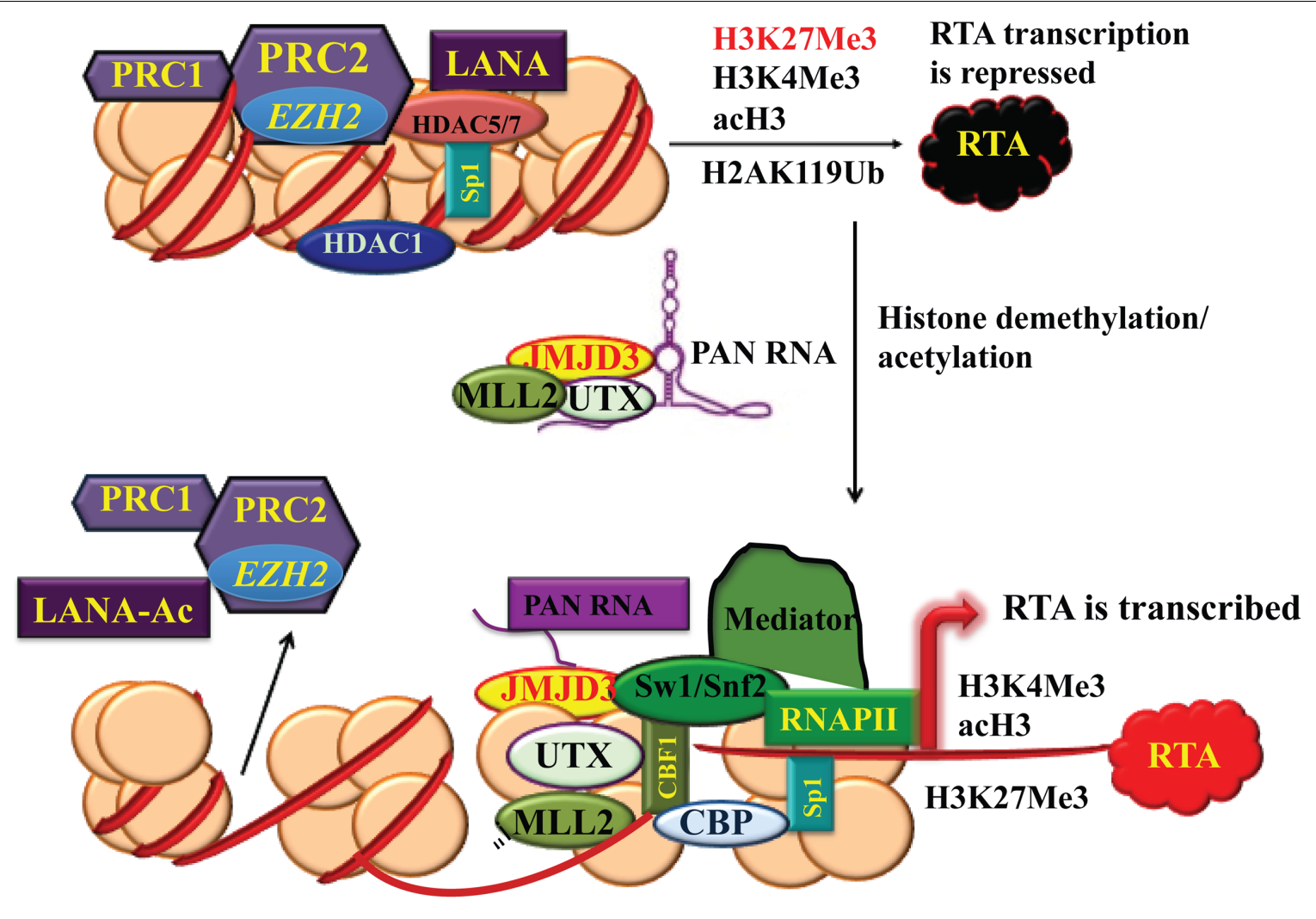

FIGURE 3 | Chromatin remodeling of KSHV RTA promoter region during latency and lytic reactivation. During latency, the chromatin of the immediate-early (IE) promoter region contains bivalent histone marks including both activating acH3, H3K4me3 and repressive H3K27me3. Polycomb repressive complex 2 (PRC2) colocalizes with H3K27me3 on RTA and PRC1 complex generates H2AK119Ub2 to repress RTA transcription. When the virus enters lytic life cycle, PRC2 dissociates from the genomic regions of IE and delayed-early (DE) genes. PAN RNA recruits histone demethylases UTX and JMJD3 and histone-lysine $\mathrm{N}$-methtttransferase 2D (KMT2D or MLL2) to the chromatin. As a result, the decrease in $\mathrm{H} 3 \mathrm{~K} 27 \mathrm{me} 3$ and increase in $\mathrm{H} 3 \mathrm{~K} 4 \mathrm{me} 3$ and acH3 results in activation of the IE and DE promoters and lytic gene expression.

addition, CTCF has been found to colocalize with cohesin at several sites throughout the KSHV genome. During latency, the major CTCF-cohesin peak resides in the first intron of the latent transcription (LANA-vCyclin-vFLIP) region and the CTCF binding site has been shown to be important for KSHV episome stability, maintenance and efficiency of de novo infection (Stedman et al., 2008). Using chromosome conformation capture technique, Kang et al. (2011) found that CTCF-cohesin binding sites are involved in DNA-loop formation with other regions. CTCF-cohesin mediates a loop between the latent transcription unit and the RTA promoter region. Depletion of cohesin subunits leads to robust reactivation of lytic gene expression (Kang et al., 2011; Li et al., 2014), suggesting that the CTCFcohesin complex at the latency control region functions as a repressor of lytic transcription. Furthermore, CTCF, together with cohensin, protects the lytic control region and retain Pol II at the lytic promoter in a conformation poised for rapid response to reactivation signals (Chen et al., 2012). Taken together, the KSHV genome is organized into chromatin loop mediated by CTCFcohesin interaction and the dynamic linkages between regions of the viral genome insulate and coordinate latent and lytic gene expression.

\section{Regulation of Reactivation at RNA Level by microRNAs}

Viruses encode microRNAs. Similar to cellular microRNAs, viral miRNAs target host immune system, cell cycle regulation, cell apoptosis, and are responsible for viral pathogenesis or oncogenesis. Twelve KSHV pre-miRNAs (miR-K1 miR-K12), encoding 25 mature miRNAs, were identified within the KSHV genome (Cai et al., 2005; Samols et al., 2005). These miRNA genes are clustered in the latency-associated region and highly expressed in latently infected primary effusion lymphoma cells (Gottwein and Cullen, 2008). Substantial evidence supports a role of some viral miRNAs in maintenance of viral latency, either directly or indirectly. A recombinant KSHV with a deletion of miR-K1-11 ( $\Delta \mathrm{miR})$ was found to consistently express higher levels of RTA mRNA than wild-type virus (Lu F. et al., 2010). In particular, miR-K9 targets the $3^{\prime} \mathrm{UTR}$ of RTA mRNA and suppresses RTA and lytic reactivation (Bellare and Ganem, 2009; Lin and Ganem, 2011). miR-K3 indirectly represses RTA by targeting nuclear factor I/B (NFIB, a transcription factor) that activates RTA promoter (Lu C.C. et al., 2010) (Figure 1). Knockdown of KSHV miR-K3 and miR-K11 increased expression of lytic genes as well as virus production from latently 
infected PEL cells. These two viral miRNAs contribute to maintenance of latency by decreasing RTA expression indirectly, presumably via down-regulation of $\mathrm{MYB}, \mathrm{C} / \mathrm{EBP} \alpha$, and Ets-1, and possibly other host transcription factors (Plaisance-Bonstaff et al., 2014).

Kaposi's sarcoma-associated herpesvirus-encoded miRNAs were also found to influence epigenetic regulation of viral latency. Comparison of epigenetic marks in $\Delta$ miR-KSHV revealed decreases in $\mathrm{H} 3 \mathrm{~K} 9 \mathrm{me}$ and increases in $\mathrm{AcH} 3$ as well as a striking loss of DNA methylation throughout the viral genome ( $\mathrm{Lu} \mathrm{F}$. et al., 2010). miR-K4-5p was found to target retinoblastoma (Rb)like protein 2 ( $\mathrm{Rbl} 2)$, which is a known repressor of DNA methyl transferase $3 \mathrm{a}$ and $3 \mathrm{~b}$ mRNA transcription (Lu C.C. et al., 2010). Thus, KSHV miRNA targets multiple pathways to maintain the latent state of the KSHV genome, including repression of Rta and regulation of epigenetic reprogramming.

Several KSHV miRNAs, miR-K3, miR-K10a, and miR-K11, act as viral analogs of the human cellular miRNAs miR155, miR-142-3p, and miR-23, respectively. These cellular and viral miRNAs share the repertoire of targeted genes (Gottwein et al., 2007, 2011; Skalsky et al., 2007; Manzano et al., 2013). KSHV miR-K10 shares the same seed sequence with cellular miR-142-3p and targets TGF- $\beta$ type II receptor in PEL and KSHV-infected endothelial cells (Lei et al., 2012). KSHV miR-K1 was reported to directly target and repress of cellular protein $\mathrm{I} \kappa \mathrm{B} \alpha$, the primary inhibitor of NF- $\kappa \mathrm{B}$ (Lei et al., 2010). By repressing $\mathrm{I} \kappa \mathrm{B} \alpha$, miR-K1 activates NF- $\kappa \mathrm{B} / \mathrm{IL}-$ 6/STAT3 signaling and functions as an oncogene (Chen et al., 2016).

\section{REGULATION OF LYTIC DNA REPLICATION}

The cascade of IE and DE gene expression leads to lytic DNA replication. KSHV lytic DNA replication initiates at an origin (ori-Lyt) and requires trans-acting elements, both viral and cellular. Unlike viral latent DNA replication that initiates at ori- $P$ and proceeds bi-directionally, the lytic replication initiates from a distinct origin (ori-Lyt) and proceeds via a rolling-circle fashion. Unlike viral latent DNA replication that depends on host cellular DNA polymerase and accessory factors, the lytic replication utilizes its own DNA polymerase and other factors. Unlike viral latent DNA replication that is in synchrony with the host cell to maintain a stable number of viral DNA episomes in each cell, the lytic DNA is amplified hundreds-fold during lytic replication. Through a rolling-circle mechansim, viral lytic DNA replication results in the generation of concatemeric genomic DNA that is subsequently cleaved into $170 \mathrm{~kb}$ long genomes during packaging.

\section{Origins of Lytic DNA Replication}

Two duplicated copies of lytic DNA replication origin [referred to as ori-Lyt (L) and ori-Lyt (R)] were identified in the $\mathrm{KSHV}$ genome, located between open reading frames K4.2 and $\mathrm{K} 5$ and between $\mathrm{K} 12$ and ORF71, respectively (AuCoin et al., 2002; Lin et al., 2003). These two ori-Lyts share an almost identical $1.1 \mathrm{~kb}$ core component sequence, followed by a $600 \mathrm{bp}$ GC-rich repeats that are represented as 20 and 30 bp tandem arrays (Lin et al., 2003). Each $1.7 \mathrm{~kb}$ ori-Lyt sequence is necessary and sufficient as a cis-acting signal for KSHV lytic DNA replication (Lin et al., 2003). Four motifs and regions within the $1.7 \mathrm{~kb}$ ori-Lyt sequence were identified to be essential for the initiation of DNA replication. First, an 18bp AT-palindromic sequence is seen in both ori-Lyt (L) and ori-Lyt (R) (Figure 4A) and deletion of the palindrome or introduction of GC pairs in the sequence abolished the DNA replication (Wang Y. et al., 2004). Such an AT-rich palindrome sequence is believed to facilitate DNA unwinding and enhance helicase activity during DNA replication (Challberg and Kelly, 1989; DePamphilis, 1993). Second, eight C/EBP binding motifs that are organized as four spaced $\mathrm{C} / \mathrm{EBP}$ palindromic pairs within a 240-bp sequence were found to be important for viral lytic replication (Figure 4A) (Wu et al., 2003b; Wang Y. et al., 2004). Each palindrome contains two head-to-head CCAAT consensus motifs that are separated by a 13- or 12-bp spacer sequence. $\mathrm{C} / \mathrm{EBP} \alpha$ is found to bind to some of the $\mathrm{C} / \mathrm{EBP}$ palindromes and the viral protein $\mathrm{K} 8 / \mathrm{KbZIP}$ associates with ori-Lyt, likely through piggybacking on the $\mathrm{C} / \mathrm{EBP} \alpha$ (Wang Y. et al., 2004; Wang et al., 2006). Third, an RRE adjacent to a TATA box was found at the end of $1.1 \mathrm{~kb}$ ori-Lyt core element (near the $600 \mathrm{bp}$ GC-rich repeats) (Figure $\mathbf{4 A}$ ). This motif functions as a transcriptional promoter that directs a transcription of a $1.4 \mathrm{~kb}$ RNA containing GC-rich repeats in the ori-Lyt-L. But in ori-Lyt$R$, the equivalent promoter controls the synthesis of $\mathrm{K} 12 / \mathrm{T} 0.7$ RNA that also contains GC-rich repeats (Wang $Y$. et al., 2004). The transcription events under the control of these promoters are essential for DNA replication from these oriLyts, as premature termination of the transcription by inserting an artificial polyadenylation signal upstream of the GC-rich repeats completely abolished the DNA replication (Wang Y. et al., 2004). In addition, the RRE also plays a role in recruiting pre-replication complexes, composed of RTA, K8 and six core machinery proteins, to the ori-Lyt DNA (Wang et al., 2006). Forth, the 600-bp GC-rich tandem repeat sequences are also indispensable for ori-Lyt-dependent DNA replication (Lin et al., 2003).

The biological significance of the existence of two ori-Lyts in the KSHV genome is still elusive. A study with the recombinant KSHVs in which one or both of the ori-Lyts were removed from the viral genome demonstrated that ori-Lyt-L is sufficient to propagate the viral genome in Vero cells whereas ori-Lyt$R$ alone seems inert to direct amplification of viral DNA (Xu et al., 2006). It is possible that two similar but not identical oriLyts in KSHV have distinct preferences for certain cell lines or modes of infection, therefore multiple ori-Lyts in a viral genome may provide optimal virus fitness for different host cell types and tissues. This hypothesis was recently validated in MHV-68 where two ori-Lyts are differentially bound by different proteins and alteration of the expression of these proteins affected the replication of mutant viruses lacking either the left or the right ori-Lyt (Sattler et al., 2016). 


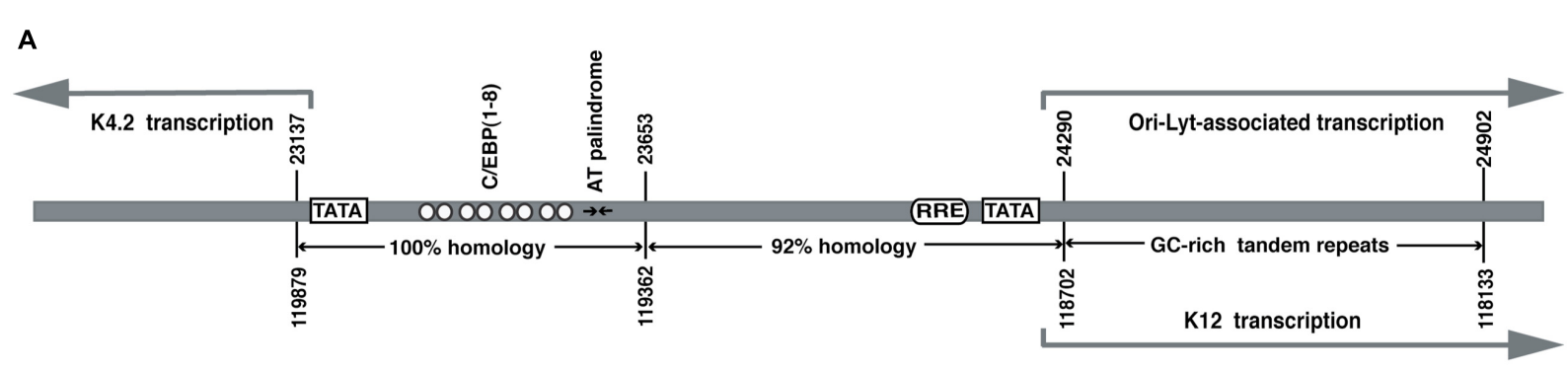

B

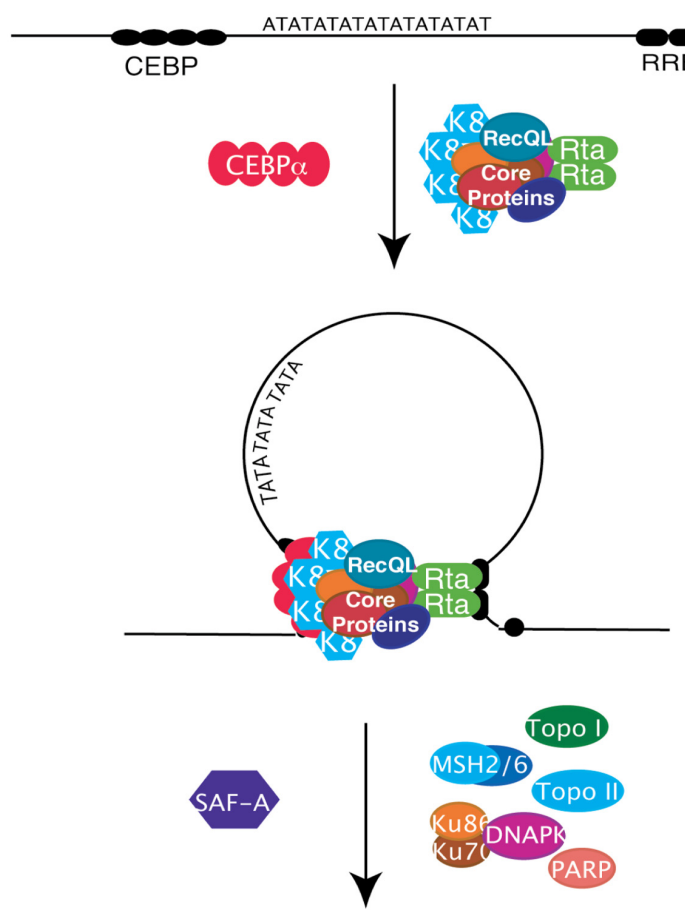

Nuclear Matrix/Scaffold

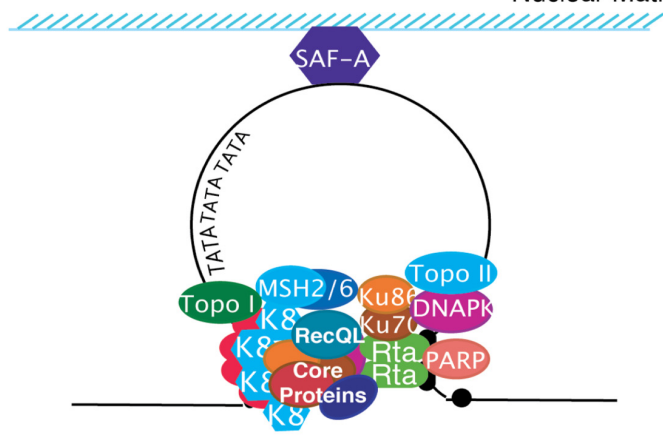

FIGURE 4 | Structure of the KSHV origin of DNA replication (ori-Lyt) and formation of viral replication initiation complex formation. (A) Ori-Lyt-R and ori-Lyt-L are superimposed to show their commonalities. The positions of various characteristic motifs (TATA boxes, C/EBP binding motifs, AT palindrome, RRE and GC tandem repeats) are as indicated. The homologies of subregions between two ori-Lyts are compared and shown on the bottom. (B) Model for formation of pre-replication complex and replication initiation complex on KSHV ori-Lyt. Six core replication proteins form pre-replication complex. The pre-replication complex is then loaded at a KSHV ori-Lyt by a two-point-contact through RTA and K8, each of which interacts with their binding motifs in the ori-Lyt. The interaction may lead to looping and distortion of the ori-Lyt DNA. Furthermore, some cellular proteins are also recruited to the complexes. RecQL is likely to be a component of pre-replication complex and recruited to ori-Lyt together with viral core replication proteins in the complex through K8 and RTA. The loading of the pre-replication complex on ori-Lyt may cause structural changes of ori-Lyt DNA that facilitates the recruiting of more cellular proteins, including MSH2/6 and DNA-PK/Ku86/70, to the ori-Lyt. Scaffold attachment factor A (SAF-A) binds directly to ori-Lyt DNA and may tether the ori-Lyt DNA to the nuclear scaffold or matrix for efficient DNA replication (Modified from Wang Y. et al., 2004). 


\section{Trans-Acting Elements Required for ori-Lyt-Dependent DNA Replication}

Two viral proteins, namely RTA and K8/K-bZip, recognize and bind to ori-Lyt in a sequence specific manner and are suggested to function as ori-Lyt binding proteins (OBPs). RTA binds to an RRE in ori-Lyt. RTA plays dual roles in ori-Lyt-dependent DNA replication. As mentioned earlier, RTA binds to the RRE within ori-Lyt and functions as a transcription activator to promote the transcription of ori-Lyt-associated transcripts (T1.4 RNA from ori-Lyt-L and K12/T0.7 RNA from ori-Lyt-R). In addition, RTA is also responsible for the recruiting of pre-replication complex to the ori-Lyt through its binding to the RRE and interacting with other core replication machinery proteins (Wang et al., 2006). RTA is a component of the viral pre-replication complexes composed of at least six core replication proteins, K8/K-bZIP, and RTA. RTA, together with K8/K-bZip (see below), mediates the loading of the pre-replication complex on the ori-Lyt DNA. Deletion or mutation of the RRE abolished the association of replication proteins with ori-Lyt DNA (Wang Y. et al., 2004; Wang et al., 2006).

$\mathrm{K} 8 / \mathrm{KbZIP}$ was demonstrated to bind to ori-Lyt DNA as well (Lin et al., 2003). The binding site was mapped to the C/EBP palindromes in KSHV ori-Lyts. However, K8 does not bind to ori-Lyt DNA directly but through piggybacking on DNAbound C/EBP $\alpha$ (Figure 4B) (Wu et al., 2003a,b; Wang Y. et al., 2004). A transient cotransfection-replication assay demonstrated an essential role of $\mathrm{K} 8$ in ori-Lyt-dependent DNA replication as omission of K8 expression plasmid in the co-transfection led to lack of detectable DNA replication (AuCoin et al., 2004).

Both RTA and K8 are able to interact with core replication machinery proteins and recruit these proteins to ori-Lyt DNA to form a pre-replication complex (Wang et al., 2006). The core replication machinery proteins include a DNA polymerase (POL), a polymerase processivity factor (PPF), a single-stranded DNA binding protein (SSB), a helicase (HEL), a primase (PRI), and a primase-associated factor (PAF). Co-expression of these proteins and the OBPs (RTA and K8/KbZIP) in eukaryotic cells is sufficient to support DNA replication of a plasmid containing a KSHV ori-Lyt (AuCoin et al., 2004).

\section{Formation of Replication Initiation Complex and Proceeding of KSHV ori-Lyt-Specific DNA Replication}

There were two models proposed for the formation of herpesviral replication initial complex on ori-Lyt DNA. (1) Herpesviral lytic replication initiates with the binding of OBPs to ori-Lyt elements. Subsequently, the OBPs recruit DNA replication enzymes and accessory factors to the origin where viral replication complex forms. (2) Viral pre-replication complexes composed viral replication core machinery proteins and $\mathrm{OBP}(\mathrm{s})$ are formed in solution and subsequently loaded on ori-Lyt DNA to form viral replication complex. Experimental evidences support the latter model for KSHV ori-Lyt-dependent DNA replication. Both K8/K-bZip and RTA are components of a multi-protein complex composed of the six viral replication core machinery proteins (POL, PPF, SSB, HEL, PRI, and PAF). The complex, designated pre-replication complex, forms in solution regardless of the presence of the viral genomic DNA (Wu et al., 2001; Wang et al., 2006) and binds to DNA fragments with the K8 binding region (the C/EBP cluster) or RRE, respectively, suggesting K8/KbZip and RTA can independently mediated the association of pre-replication complex with ori-Lyt DNA through their specific binding sites (Wang et al., 2006). These findings leads to a model for recruiting of pre-replication complexes to ori-Lyt by RTA and K8, which is illustrated in Figure 4B. The two-contact-point binding may bring the two ends of the ori-Lyt element together, looping the DNA between the K8 and RTA binding sites. The 18bp AT palindrome sequence is located in the center of the loop. The looping causes bending and distortion of the ori-Lyt DNA, facilitating unwinding of the DNA sequence (Wang et al., 2006).

In addition to viral components, many cellular proteins are also incorporated in the replication initiation complex. They include topoisomerases (Topo) I and II, RecQL, poly(ADPribose) polymerase I (PARP-1), DNA-PK, Ku86/70 autoantigens, $\mathrm{MSH} / 6$, and scaffold attachment factor A (SAF-A) (Figure 4B). RecQL appears to associate with pre-replication complexes and be recruited to ori-Lyt through RTA and K8. Topo I and II, PARP-1, DNA-PK, Ku86, and MSH2 were not detected in prereplication complexes but were present in replication initiation complexes on ori-Lyt (Wang et al., 2008). Topo I and II have been demonstrated to be essential for viral lytic replication as depletion of Topo I and II using an shRNA knock down approach severely inhibited viral lytic DNA replication as well as virion production (Gonzalez-Molleda et al., 2012).

\section{REGULATION OF LATE GENES}

The genes coding for KSHV structural proteins (capsid proteins, tegument protein, envelope glycoproteins, and relevant auxiliary factors) do not express until viral lytic DNA replication begins. This class of genes is designated late (L) genes. Among all three herpesviral subfamilies (alpha-, beta- and gamma-herpesviridae), the late gene regulation share similar features (Homa et al., 1986; Johnson and Everett, 1986; Anders et al., 2007). (1) The promoters of late genes are typically very simple defined by small regions surrounding the TATA motif. For example, KSHV K8.1 promoter consists of a 24-bp sequence with a TATA-like core (AATATTAAAGGG) and is regulated in KSHV lytic replicating cells by trans (Tang et al., 2004). (2) Late genes expression is coupled with viral lytic DNA replication as expression of an authentic late gene can be blocked by a viral DNA polymerase inhibitor PAA. The activity of the K8.1 promoter can be enhanced ( $>15$-fold) by a KSHV ori-Lyt sequence in cis. The promoter activity is sensitive to PAA with an inhibition up to $97 \%$, fully imitating the activation of an authentic late gene in response to viral lytic replication (Tang et al., 2004).

The trans-acting elements that control KSHV late gene expression have been characterized recently. It was shown that KSHV late gene expression requires the coordination of six DE viral proteins, namely ORFs $18,24,30,31,34$, and 66 , which form a late gene transcription preinitiation complex (vPIC) (Brulois et al., 2015; Davis et al., 2015a). Furthermore, ORF24 is 
a TATA box binding protein (TBP) homolog that recruits RNA polymerase II to the late promoter for the transcription from the promoter (Davis et al., 2015b). The mechanism that couples late gene activation to viral DNA replication has not yet been elucidated. A putative model has been that the restriction of late gene activation may attribute to viral genome structure and viral DNA replication temporally remodels the chromatin structure, therefore relieving the restrain for the late gene expression and allowing the vPIC binds to the TATA box region of late gene promoter.

\section{ASSEMBLY OF VIRAL PARTICLES AND RELEASE OF INFECTIOUS VIRIONS}

Lytic replication of viral genomic DNA and synthesis of viral lytic proteins leads the cascade to the next phase of KSHV lytic replication - viral particle assembly and virion release. Assembly of viral particle is autocatalytic and intrinsic information governing the assembly process is borne in the viral structure proteins. However, some cellular protein and machineries are harnessed or usurped by virus to assist viral particle transport and membrane budding.

Kaposi's sarcoma-associated herpesvirus assembly and egress is a multiple-step process. Although the details of many steps in the process are largely unknown, the general model for herpesviral particle assembly is as follows: (1) Newly synthesized viral DNA is incorporated into preformed capsid in the nucleus; (2) intranuclear capsid leaves the nucleus by primary envelopment at the inner nuclear membrane and the primary envelope then fuses with the outer leaflet of the nuclear membrane, releasing capsids into the cytoplasm; (3) capsids acquire tegument in the cytoplasm; (4) final envelopment occurs by budding into Golgi-derived vesicles; (5) mature virions are released after fusion of the vesicle membrane with the plasma membrane of the cell (reviewed in Mettenleiter, 2002; Mettenleiter et al., 2009). This model appears to be true for KSHV virion assembly (Figure 5).

\section{Formation of Nucleocapsids and Nuclear Egress of KSHV Capsid}

All herpesviruses including KSHV have thick-walled icosahedral nucleocapsids, $\sim 125 \mathrm{nM}$ in diameter. The nucleocapsid of $\mathrm{KSHV}$ is composed of five capsid proteins, namely the major capsid protein (MCP) in hexameric and pentameric capsomers; triplex proteins 1 and 2 (TRI-1 and TRI-2, respectively) forming heterotrimers in a 1:2 ratio to connect the capsomers; the smallest capsid protein (SCP) stabilizing the capsid by crosslinking neighboring subunits of the MCP of hexons (Dai et al., 2015), and the portal protein (ORF43) forming a dodecameric structure for DNA genome packaging at one of the 12 icosahedral vertices (Trus et al., 2001). The assembly of herpesvirus capsid appears to be a spontaneous process, as the capsid of HSV-1 (herpes simplex virus 1, an alphaherpesvirus) can be assembled in a cell-free system (Newcomb et al., 1994, 1996). Assembly of herpesviral procapsid may initiate at aggregation of capsid

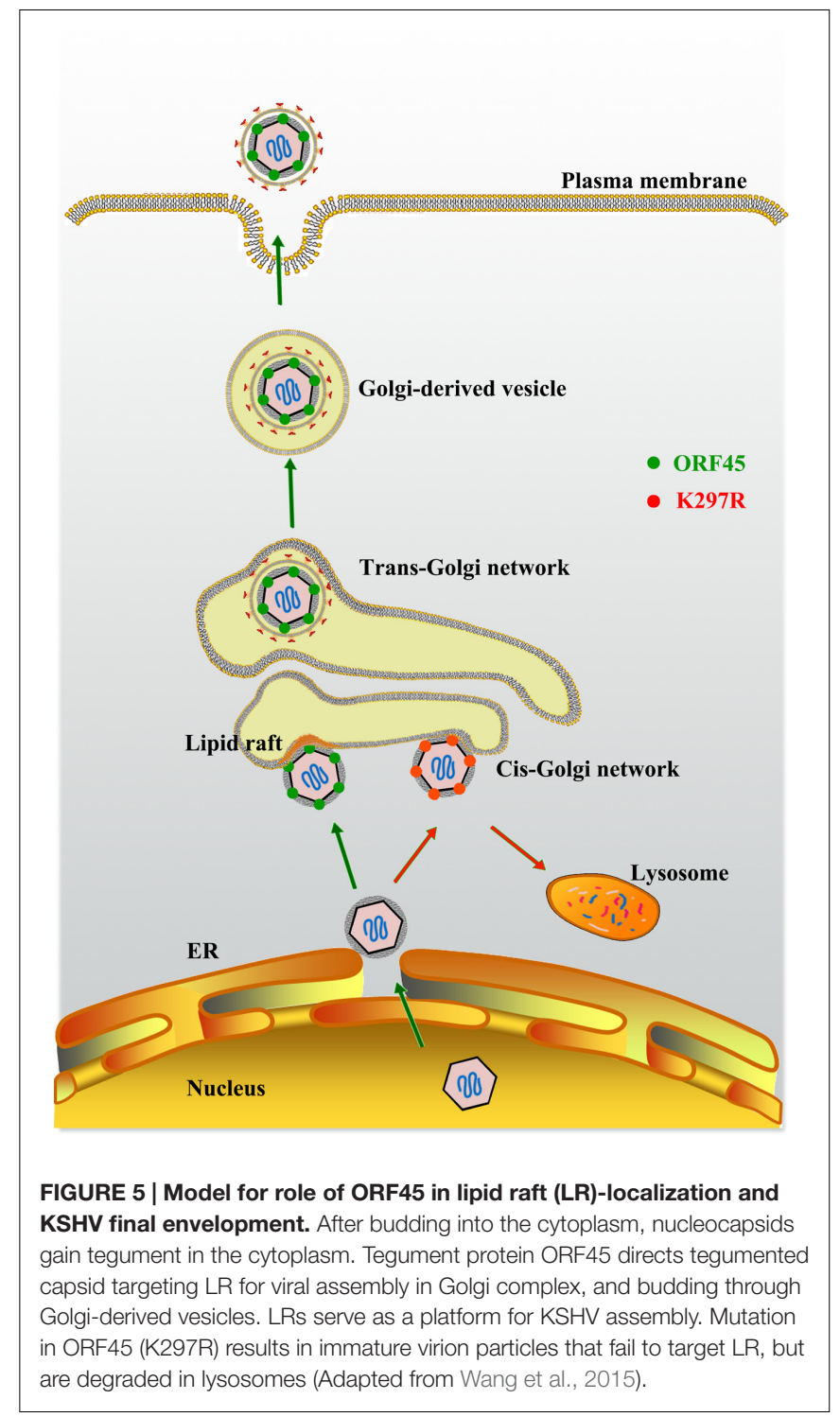

proteins to produce protomers, which then assemble into higherorder procapsid structures (Aksyuk et al., 2015). It is likely to be true with KSHV capsids.

After the procapsid is formed, newly synthesized viral genomic DNA enters it through a DNA-packaging/ejection portal complex located at only one of the vertices of the capsid (Deng et al., 2007). The DNA-packaging/ejection portal complex is composed of a portal protein (PORT), which is encoded by ORF43 in the KSHV genome.

Like all herpesviruses, KSHV capsids are formed in the nucleus of infected cells, while final maturation occurs in the cytoplasm. To access the final assembly compartment, intranuclear capsids have to cross the nuclear envelope barrier. The current model for nuclear egress of herpesviral capsid is the envelopment-deenvelopment-reenvelopment model (Mettenleiter, 2002). In this model, mature nucleocapsids undergo a process of primary envelopment through the inner 
nuclear membrane and bud into the perinuclear space as enveloped viral particles. This is followed by deenvelopment at the outer nuclear membrane, releasing unenveloped capsids in the cytoplasm. Herpesviruses may usurp cellular endosomal sorting complex required for transport (ESCRT) machinery for nuclear egress (Lee et al., 2012), but the involvement of ESCRT in KSHV nuclear egress has not yet been proven.

\section{Tegument Proteins and Tegumentation}

After nuclear egress, KSHV capsids acquire tegument proteins in the cytoplasm, which will be the tegument in the mature virion particles. The tegument used to be considered as an amorphous layer of proteins, but recent studies indicated ordered tegument structures in HSV-1 (Zhou et al., 1999), HCMV (Chen et al., 1999), MHV-68 (Dai et al., 2008), and KSHV (Dai et al., 2014). In de novo infection, tegument proteins play roles in viral entry, gene expression, and immune evasion. KSHV tegument protein ORF45 was demonstrated to antagonize innate immunity of host cells against the virus by blocking IRF-7 activation and nuclear translocation during de novo infection (Zhu et al., 2002, 2010; Sathish and Yuan, 2011). ORF52 subverts cytosolic DNA sensing by directly inhibiting cGAS enzymatic activity through a mechanism involving both cGAS binding and DNA binding ( $\mathrm{Wu}$ et al., 2015b).

The tegumentation process is believed to be autocatalyzed through dynamic and intricate interactions amongst tegument protein themselves as well as with capsid. Composition of KSHV virions were analyzed using the state of the art proteomics approaches (Bechtel et al., 2005; Zhu et al., 2005). Interactions of the KSHV tegument proteins with different virion proteins have been systematically investigated, which led to the revelation of a virion-wide protein interaction network (Rozen et al., 2008). ORF64 encodes a $290-\mathrm{kDa}$ tegument protein and the protein interaction map indicates a diverse interaction potential of ORF64 with many virion proteins. They include three viral capsid proteins, namely MCP, Triplex 1 and 2 (TRI-1 and TRI-2), suggesting an attachment of ORF64 to the icosahedral capsid structure (Rozen et al., 2008). A three-dimensional image reconstructed from a cryo-electron microscopic study of KSHV tegumented capsid particles revealed a density of three helices bundle that is distributed around the capsid vertices and interacts with penton and surrounding triplexes. The visualized filamentous material is likely to be ORF64 (Dai et al., 2014), consistent with the finding from the protein interaction study of ORF64 (Rozen et al., 2008).

Kaposi's sarcoma-associated herpesvirus ORF64 also interacts with a number of tegument proteins including ORFs 11, 21, 33, $45,63,75$ and itself, leading to a hypothesis that ORF64 is a scaffold protein, functioning as a major hub and recruiting other tegument proteins during $\mathrm{KSHV}$ tegumentation. In addition, ORF64 also interacts with some envelope glycoproteins (gB, $\mathrm{gM}$, and $\mathrm{gH}$ ) (Rozen et al., 2008). This finding justifies a rather peculiar behavior of ORF64 wherein it can be degraded when intact virion particles are treated with trypsin, suggesting the association of ORF64 with the viral envelope (Zhu et al., 2005). The interaction of ORF64 with viral glycoproteins is consistent with a hypothetical role of this protein in positioning the DNA-filled viral particles at the Golgi-derived vesicles through interaction with envelope glycoproteins, thus facilitating secondary envelopment processes.

Roles of other tegument proteins in tegumentation processes have been reported one after another in KSHV as well as related gamma-herpesviruses such as MHV-68. ORF33, ORF38, and ORF52 were all found to participate in tegumentation as deficiency of each of these proteins results in change of viral particle components. Loss of ORF33 or ORF38 in null-mutant recombinant viruses abolishes the recruitment of ORF45 into the KSHV and MHV-68 tegument (Guo et al., 2009; Wu et al., 2015a). ORF52-null recombinant KSHV and MHV-68 exhibited partially tegumented capsids with the absence of ORF45 (Bortz et al., 2007; Wang et al., 2012; Li et al., 2016). In summary, KSHV tegumentation is a self-assembly process following an intricate network of protein-protein interactions.

\section{Final Envelopment and Egress}

Kaposi's sarcoma-associated herpesvirus particles acquire their membranous envelope by budding into the lumen of cytoplasmic vesicles. This process is initiated by viral components, which recognize the budding site and recruit cellular cargo transport and sorting machinery to the site to complete the budding process. Herpesvirus budding and virion maturation, especially for gamma-herpesviruses, is poorly characterized. However, recent progress has demonstrated the roles of KSHV tegument proteins in orchestrating the final envelopment and budding process (Wang et al., 2015).

As mentioned above, ORF64 associates with the viral capsid, demonstrated by a $5 \AA$ cryoEM structure of KSHV tegumented capsid (Dai et al., 2014) as well as by the interactions between KSHV ORF64 and three capsid proteins (MCP, TRI-1, and TRI-2) previously observed (Rozen et al., 2008). Other evidence suggests that ORF64 also interacts with virion envelope membrane. Thus, it is speculated that ORF64 fulfills the roles of other viral matrix proteins by interacting with the capsid with one end and attaching the viral envelope with the other end, therefore suggesting a role of ORF64 in positioning DNA-filled capsid on the membrane of TGN where viral envelopment occurs.

Then, how does a KSHV particle bud through the membranous organelle and thereby acquire its membrane? Enveloped virus budding is topologically equivalent to cellular vesiculation process (endocytosis) and multivesicular body formation (Figure 5). It is believed that herpesviruses usurps cellular membrane sorting and transport machinery to execute the budding process like HIV-1 that was shown to utilize cellular ESCRT for its budding from the plasma membrane (Votteler and Sundquist, 2013). In spite of involvement of cellular machinery in viral budding, the process has to be initiated and orchestrated by viral component(s). Recently ORF45, as an outer tegument protein in KSHV particles, was found to be responsible for co-localization of viral particles with cytoplasmic membrane vesicles that carry trans-Golgi and endosome markers (TGN46 and EEA1) and facilitates the budding of viral particles into the membrane vesicles and the release of virion particles. The ability of ORF45 to target cytoplasmic vesicle at lipid raft (LR) domain is dependent on the mono-ubiquitylation of ORF45 at 
Lys297. Mutation at Lys297 (K297R) impairs ORF45 and viral particle co-localization with trans-Golgi network and endosomes (Figure 5). Furthermore, the recombinant KSHV carrying K297R mutant ORF45 (BAC-K297R) was severely defective in producing mature and infectious virion particles in comparison to wild-type KSHV (Wang et al., 2015). This finding revealed a function of ORF45 in targeting cytoplasmic membrane vesicles (likely transGolgi network or derived vesicles), facilitating the maturation and release of virion particles.

\section{KSHV LYTIC CYCLE AND ONCOGENESIS}

A traditional concept was that the lytic cycle of a tumor virus presumably does not contribute to oncogenesis simply because the lytic cycle in general leads to lysis and death of host cells. However, accumulative evidence suggests that the KSHV lytic cycle appears to be crucial for tumorigenesis. The most compelling evidence for this notion is that regression of KS lesions or decrease in the incidence of KS development were observed after KS patients or AIDS patients at risk for KS were treated with anti-herpesviral drugs, such as ganciclovir and foscarnet, that inhibit viral lytic but not latent replication (Martin et al., 1999). Furthermore, KSHV lytic replication spreads viruses to target cells and provides paracrine regulation, contributing to tumorigenesis (Cesarman et al., 2000). In addition, a new role of lytic replication has been described in sustaining the population of latently infected cells that otherwise would be quickly lost by segregation of latent viral episomes as spindle cells divide (Grundhoff and Ganem, 2004). Thus, KSHV lytic replication and constant infection to fresh cells are crucial for viral pathogenesis and tumorigenicity.

Among the potential oncogenes identified in the KSHV genome, many are classified in the category of viral lytic genes and have been shown to primarily express in the lytic life cycle. K1 encodes a type I membrane proteins and expresses in lytic early kinetics. Its expression can be detected in KS, PEL, and multicentric Castleman's disease (MCD). Transgenic mice expressing the $\mathrm{K} 1$ gene exhibited constitutive activation of NF$\kappa \mathrm{B}$ and Oct-2, increased Lyn tyrosine kinase phosphorylation and elevated bFGF expression. Some of these mice developed spindle cell sarcomatoid tumor and plasmablastoid lymphoma (Prakash et al., 2002). ORF74-encoded vGPCR also expresses in the lytic phase with the early kinetics. vGPCR transgenic mice developed KS-like angiogenic lesions (Yang et al., 2000; Guo et al., 2003; Montaner et al., 2003). K2 encodes a vIL-6, which can be detected in MCD, PEL, and KS to different extents. vIL-6 signaling results in increased VEGF expression and vascularized tumors in mice (Aoki et al., 2001; Liu et al., 2001).

The paradoxical roles of KSHV lytic cycle and lytic proteins in tumorigenesis are still elusive but can be considered in several possibilities: (1) KSHV may not effectively immortalize infected cells or provide cell growth advantage in vivo (as observed in vitro in cell culture conditions). Spontaneous lytic replication of a small portion of infected cells in a lesion or population pool is critical for maintenance of infected cell populations by replacing dead cells or the cells whose viral genome is lost with freshly infected cells; (2) It is possible that some lytic proteins are expressed outside of the traditional lytic cycle and abortive replication life cycle allows specific lytic genes to be expressed in the absence of fully lytic replication; (3) Viral lytic replication may trigger activation of cellular oncogenic pathways or those for proliferation and inflammation, which contributes to $\mathrm{KSHV}$ oncogenicity in a greater extent than the latencyassociated oncogenic potential. This notion is supported by the observation that EBV lytic genes are coexpressed with cellular cancer-associated pathways revealed by an EBV transcriptome study (Arvey et al., 2012).

\section{FUTURE PERSPECTIVES}

The two life cycles (latency and lytic replication) of herpesviruses and regulated switches between them represent extremely complex mechanisms that the viruses developed in co-evolution with hosts for millions of years. This allows herpesviruses to achieve both persistent infection for lifetime of the host and efficient dissemination from its long-term reservoir to the sites of disease or of shedding to spread to new hosts. Although we have learned a lot as summarized in this review regarding these two life cycles of KSHV and the mechanisms that control the switch between the two cycles, it might be just a tip of an iceberg. Many important questions remain elusive but progress is expected in the following aspects.

First, the regulatory mechanisms that control the switch between the two viral life cycles are complex and sophisticated. New categories of regulators and novel layers of control mechanisms are expected to emerge. Revelation of PAN RNA in epigenetic regulation of KSHV reactivation (Rossetto et al., 2013; Rossetto and Pari, 2014) is likely to be an overture that will be followed by a new chapter of regulation of viral latency and reactivation by non-coding RNAs, both viral and cellular. Furthermore, the microPeptide-mediated manipulation of protein function that adds a new dimension of biological regulation is on the horizon (Jaber and Yuan, 2013).

Second, increasing evidence suggests that contributions of KSHV lytic life cycle to oncogenesis are far greater than what we thought before. Is KSHV reactivation and lytic replication required for tumorigenesis by increasing viral titer to facilitate viral dissemination to the sites of tumor? At least $12 \mathrm{KSHV}$ lytic proteins have been demonstrated to involve oncogenesis including transforming, pro-angiogenic, pro-growth, anti-apoptotic, or immuno-modulatory functions. Do these viral lytic proteins thus serve as direct effectors of the disease phenotypes and do lytically infected cells serve not only as reservoirs of infectious virus but also as reservoirs of pathogenic viral proteins? Research on these questions will provide novel insights into pathogenesis of tumor viruses.

Third, KSHV lytic replication can be considered to design therapeutic strategies for treatment and prevention of KS due to its etiological role in KS of all types (classic KS, endemic KS, AIDS-associated KS, and IRIS-KS in the HAART era). There is currently no definitive cure for KS. Classic cancer therapies are generally used to treat KS patients, which include 
surgical excision and radiation therapy for patients with a few lesions in a limited area and chemotherapy for patients with extensive or recurrent KS (Antman and Chang, 2000). The chemotherapeutics, which have been approved by the FDA and are often used, include liposomal anthracycline products (liposomal doxorubicin or liposomal daunorubicin), paclitaxel, and interferon- $\alpha$ (Potthoff and Brockmeyer, 2007). However, these therapeutic agents do not target the etiological virus and the tumor response to any chemotherapeutic regimen is only transient. In AIDS-associated KS, HAART regimens are associated with regression in the size and number of existing KS lesions (Lebbe et al., 1998). Despite its dramatic decrease in frequency since the advent of HAART, KS remains the most common AIDS-associated cancer (Boshoff and Weiss, 2002; Shiels et al., 2011). In addition, as experience with HAART has grown, a new HAART-associated syndrome, namely immune reconstitution inflammatory syndrome or IRIS, emerged. In a subset of HIV-seropositive individuals, initiation of HAART in the setting of advanced HIV infection results in a paradoxical clinical worsening of existing infection or the appearance of a new condition including $\mathrm{KS}$ in a process (Shelburne and Hamill, 2003). Recently new cases of pulmonary KS as a result of non-compliance HAART therapy have been reported (Epelbaum et al., 2016). As IRIS-KS is the result of responses by a recovered immune system to KS-causing pathogen, i.e.,

\section{REFERENCES}

Aksyuk, A. A., Newcomb, W. W., Cheng, N., Winkler, D. C., Fontana, J., Heymann, B. J., et al. (2015). Subassemblies and asymmetry in assembly of herpes simplex virus procapsid. mBio 6:e01525-15. doi: 10.1128/mBio.01525-15

Anders, D. G., Kerry, J. A., and Pari, G. S. (2007). "DNA synthesis and late viral gene expression," in Human Herpesviruses: Biology, Therapy, and Immunoprophylaxis, eds A. Arvin, G. Campadelli-Fiume, E. Mocarski, P. S. Moore, B. Roizman, R. Whitley, et al. (Cambridge: Cambridge University Press), 19.

Antman, K., and Chang, Y. (2000). Kaposi's sarcoma. N. Engl. J. Med. 342, 1027-1038. doi: 10.1056/NEJM200004063421407

Aoki, Y., Yarchoan, R., Wyvill, K., Okamoto, S., Little, R. F., and Tosato, G. (2001). Detection of viral interleukin-6 in Kaposi sarcoma-associated herpesviruslinked disorders. Blood 97, 2173-2176. doi: 10.1182/blood.V97.7.2173

Arvey, A., Tempera, I., Tsai, K., Chen, H. S., Tikhmyanova, N., Klichinsky, M., et al. (2012). An atlas of the Epstein-Barr virus transcriptome and epigenome reveals host-virus regulatory interactions. Cell Host Microbe 12, 233-245. doi: 10.1016/j.chom.2012.06.008

AuCoin, D. P., Colletti, K. S., Cei, S. A., Papouskova, I., Tarrant, M., and Pari, G. S. (2004). Amplification of the Kaposi's sarcoma-associated herpesvirus/human herpesvirus 8 lytic origin of DNA replication is dependent upon a cis-acting AT-rich region and an ORF50 response element and the trans-acting factors ORF50 (K-Rta) and K8 (K-bZIP). Virology 318, 542-555. doi: 10.1016/j.virol. 2003.10.016

AuCoin, D. P., Colletti, K. S., Xu, Y., Cei, S. A., and Pari, G. S. (2002). Kaposi's sarcoma-associated herpesvirus (human herpesvirus 8) contains two functional lytic origins of DNA replication. J. Virol. 76, 7890-7896. doi: 10.1128/JVI.76.15. 7890-7896.2002

Ballestas, M. E., Chatis, P. A., and Kaye, K. M. (1999). Efficient persistence of extrachromosomal KSHV DNA mediated by latency-associated nuclear antigen. Science 284, 641-644. doi: 10.1126/science.284.5414.641

Bechtel, J. T., Winant, R. C., and Ganem, D. (2005). Host and viral proteins in the virion of Kaposi's sarcoma-associated herpesvirus. J. Virol. 79, 4952-4964. doi: 10.1128/JVI.79.8.4952-4964.2005
KSHV, treatment of KSHV-seropositive, HIV-positive patients with a combination of antiretroviral (HAART) and anti-KSHV chemotherapeutics is expected to yield positive results. However, currently there are no effective drugs targeting KSHV available. The recent progress in understanding of KSHV reactivation provides opportunities to develop targeted drugs against KSHV lytic replication. For example, RTA is unique transcription factor. Its DNA binding region does not contain any wellcharacterized DNA binding motifs and the overall protein shows no homology with any known cellular transcriptional activators. Therefore, RTA is an attractive target for antiviral therapy. In addition, virion assembly and egress processes are expected to be effective targets for broad-spectrum antiviral drugs.

\section{AUTHOR CONTRIBUTIONS}

KA and YY contribute to the writing, figure-making, and proofreading for this review article.

\section{FUNDING}

This work is supported by a NIH grant P01CA174439.

Bellare, P., and Ganem, D. (2009). Regulation of KSHV lytic switch protein expression by a virus-encoded microRNA: an evolutionary adaptation that finetunes lytic reactivation. Cell Host Microbe 6, 570-575. doi: 10.1016/j.chom.2009. 11.008

Bhatt, A. P., and Damania, B. (2013). AKTivation of PI3K/AKT/mTOR signaling pathway by KSHV. Front. Immunol. 4:401. doi: 10.3389/fimmu.2012. 00401

Bortz, E., Wang, L., Jia, Q., Wu, T. T., Whitelegge, J. P., Deng, H., et al. (2007). Murine gammaherpesvirus 68 ORF52 encodes a tegument protein required for virion morphogenesis in the cytoplasm. J. Virol. 81, 10137-10150. doi: 10.1128/ JVI.01233-06

Boshoff, C., and Weiss, R. (2002). AIDS-related malignancies. Nat. Rev. Cancer 2, 373-382. doi: 10.1038/nrc797

Bourboulia, D., Aldam, D., Lagos, D., Allen, E., Williams, I., Comforth, D., et al. (2004). Short-and long-term effects of highly active antiretroviral therapy on Kaposi sarcoma-associated herpesvirus immune responses and viraemia. AIDS 18, 485-493. doi: 10.1097/00002030-200402200-00015

Bower, M., Nelson, M., Young, A. M., Thirlwell, C., Newsom-Davis, T., Mandalia, S., et al. (2005). Immune reconstitution inflammatory syndrome associated with Kaposi's sarcoma. J. Clin. Oncol. 23, 5224-5228. doi: 10.1200/ JCO.2005.14.597

Brown, H. J., Song, M. J., Deng, H., Wu, T.-T., Cheng, G., and Sun, R. (2003). NF-к-B inhibits gammaherpesvirus lytic replication. J. Virol. 77, 8532-8540. doi: 10.1128/JVI.77.15.8532-8540.2003

Brulois, K., Wong, L.-Y., Lee, H.-R., Sivadas, P., Ensser, A., Feng, P., et al. (2015). The association of Kaposi's sarcoma-associated herpesvirus ORF31 with ORF34 and ORF24 is critical for late gene expression. J. Virol. 89, 6148-6154. doi: 10.1128/JVI.00272-15

Bu, W., Carroll, K. D., Palmeri, D., and Lukac, D. M. (2007). Kaposi's sarcomaassociated herpesvirus/human herpesvirus 8 ORF50/Rta lytic switch protein functions as a tetramer. J. Virol. 81, 5788-5806. doi: 10.1128/JVI.00140-07

Bu, W., Palmeri, D., Krishnan, R., Marin, R., Aris, V. M., Soteropoulos, P., et al. (2008). Identification of direct transcriptional targets of the Kaposi's sarcoma-associated herpesvirus Rta lytic switch protein by conditional nuclear localization. J. Virol. 82, 10709-10723. doi: 10.1128/JVI.01012-08 
Cai, J., Lan, K., Verma, S. C., Huaxin, S., Lin, D., and Robertson, E. S. (2006). Kaposi's sarcoma-associated herpesvirus latent protein LANA interacts with HIF-1alpha to upregulate RTA expression during hypoxia: latency control under low oxygen conditions. J. Virol. 80, 7965-7975. doi: 10.1128/JVI.00689-06

Cai, Q., Cai, S., Zhu, C., Verma, S. C., Choi, J. Y., and Robertson, E. S. (2013). A unique SUMO-2-interacting motif within LANA is essential for KSHV latency. PLoS Pathog. 9:e1003750. doi: 10.1371/journal.ppat.1003750

Cai, X., Lu, S., Zhang, Z., Gonzalez, C. M., Damania, B., and Cullen, B. R. (2005). Kaposi's sarcoma-associated herpesvirus expresses an array of viral microRNAs in latently infected cells. Proc. Natl. Acad. Sci. U.S.A. 102, 5570-5575. doi: 10.1073/pnas.0408192102

Candido, E. P. M., Reeves, R., and Davie, J. R. (1978). Sodium butyrate inhibits histone deacetylation in cultured cells. Cell 14, 105-113. doi: 10.1016/00928674(78)90305-7

Cannon, M. L., and Cesarman, E. (2004). The KSHV G protein-coupled receptor signals via multiple pathways to induce transcription factor activation in primary effusion lymphoma cells. Oncogene 23, 514-523. doi: 10.1038/sj.onc. 1207021

Carroll, K. D., Bu, W., Palmeri, D., Spadavecchia, S., Lynch, S. J., Marras, S. A. E., et al. (2006). The KSHV lytic switch protein stimulates DNA binding of RBPJk/CSL to activate the notch pathway. J. Virol. 80, 9697-9709. doi: 10.1128/JVI. 00746-06

Carroll, K. D., Khadim, F., Spadavecchia, S., Palmeri, D., and Lukac, D. M. (2007). Direct interactions of Kaposi's sarcoma-associated herpesvirus/human herpesvirus 8 ORF50/Rta protein with the cellular protein octamer-1 and DNA are critical for specifying transactivation of a delayed-early promoter and stimulating viral reactivation. J. Virol. 81, 8451-8467. doi: 10.1128/JVI. 00265-07

Caselli, E., Menegazzi, P., Bracci, A., Galvan, M., Cassai, E., and Di Luca, D. (2001). Human herpesvirus-8 (Kaposi's sarcoma-associated herpesvirus) ORF50 interacts synergistically with the tat gene product in transactivating the human immunodeficiency virus type 1 LTR. J. Gen. Virol. 82, 1965-1970. doi: 10.1099/ 0022-1317-82-8-1965

Casper, C., Nichols, W. G., Huang, M. L., Corey, L., and Wald, A. (2004a). Remission of HHV-8 and HIV-associated multicentric Castleman disease with ganciclovir treatment. Blood 103, 1632-1634.

Casper, C., Redman, M., Huang, M. L., Pauk, J., Lampinen, T. M., Hawes, S. E., et al. (2004b). HIV infection and human herpesvirus- 8 oral shedding among men who have sex with men. J. Acquir. Immune Defic. Syndr. 35, 233-238.

Cattelan, A. M., Calabro, M. L., Gasperini, P., Aversa, S. M., Zanchetta, M., Meneghetti, F., et al. (2001). Acquired immunodeficiency syndrome-related Kaposi's sarcoma regression after highly active antiretroviral therapy: biologic correlates of clinical outcome. J. Natl. Cancer Inst. Monogr. 28, 44-49.

Cesarman, E., Mesri, E. A., and Gershengorn, M. C. (2000). Viral G proteincoupled receptor and Kaposi's sarcoma: a model of paracrine neoplasia. J. Exp. Med. 191, 417-422. doi: 10.1084/jem.191.3.417

Challberg, M. D., and Kelly, T. J. (1989). Animal virus DNA replication. Annu. Rev. Biochem. 58, 671-717. doi: 10.1146/annurev.bi.58.070189.003323

Chang, H., Dittmer, D. P., Chul, S.-Y., Hong, Y., and Jung, J. U. (2005). Role of notch signal transduction in Kaposi's sarcoma-associated herpesvirus gene expression. J. Virol. 79, 14371-14382. doi: 10.1128/JVI.79.22.14371-14382.2005

Chang, J., Renne, R., Dittmer, D., and Ganem, D. (2000). Inflammatory cytokines and the reactivation of Kaposi's sarcoma-associated herpesvirus lytic replication. Virology 266, 17-25. doi: 10.1006/viro.1999.0077

Chang, M., Brown, H. J., Collado, H. A., Arevalo, J. M., Galic, Z., Symensma, T. L., et al. (2005). $\beta$-Adrenoreceptors reactivate Kaposi's sarcoma-associated herpesvirus lytic replication via PKA-dependent control of viral RTA. J. Virol. 79, 13538-13547. doi: 10.1128/JVI.79.21.13538-13547.2005

Chang, P. C., Fitzgerald, L. D., Van Geelen, A., Izumiya, Y., Ellison, T. J., Wang, D. H., et al. (2009). Kruppel-associated box domain-associated protein1 as a latency regulator for Kaposi's sarcoma-associated herpesvirus and its modulation by the viral protein kinase. Cancer Res. 69, 5681-5689. doi: 10.1158/ 0008-5472.CAN-08-4570

Chang, P. C., Latricia, D., Fitzgerald, L. D., Hsia, A., Izumiya, Y., Wu, C., et al. (2011). Histone demethylase JMJD2A regulates Kaposi's sarcoma-associated herpesvirus replication and is targeted by a viral transcriptional factor. J. Virol. 85, 3283-3293. doi: 10.1128/JVI.02485-10
Chang, P. J., and Miller, G. (2004). Autoregulation of DNA binding and protein stability of Kaposi's sarcoma-associated herpesvirus ORF50 protein. J. Virol. 78, 10657-10673. doi: 10.1128/JVI.78.19.10657-10673.2004

Chang, P. J., Shedd, D., and Miller, G. (2008). A mobile functional region of Kaposi's sarcoma-associated herpesvirus ORF50 regulates DNA binding and protein abundance. J. Virol. 82, 9700-9716. doi: 10.1128/JVI.00862-08

Chang, Y., Cesarman, E., Pessin, M. S., Lee, F., Culpepper, J., Knowles, D. M., et al. (1994). Identification of herpesvirus-like DNA sequences in AIDS-associated Kaposi's sarcoma. Science 266, 1865-1869. doi: 10.1126/science.7997879

Chaudhary, P. M., Jasmin, A., Eby, M. T., and Hood, L. (1999). Modulation of the NF- $\kappa \mathrm{B}$ pathway by virally encoded death effector domains-containing proteins. Oncogene 18, 5738-5746. doi: 10.1038/sj.onc.1202976

Chen, D., Jiang, H. H., Lee, M., Liu, F., and Zhou, Z. H. (1999). Threedimensional visualization of tegument/capsid interactions in the intact human cytomegalovirus. Virology 260, 10-16. doi: 10.1006/viro.1999.9791

Chen, H. S., Wikramasinghe, P., Showe, L., and Lieberman, P. M. (2012). Cohesins repress Kaposi's sarcoma-associated herpesvirus immediate early gene transcription during latency. J. Virol. 86, 9454-9464. doi: 10.1128/JVI.00787-12

Chen, J., Ueda, K., Sakakibara, S., Okuno, T., Parravicini, C., Corbellino, M., et al. (2001). Activation of latent Kaposi's sarcoma-associated herpesvirus by demethylation of the promoter of the lytic transactivator. Proc. Natl. Acad. Sci. U.S.A. 98, 4119-4124. doi: 10.1073/pnas.051004198

Chen, M., Sun, F., Han, L., and Qu, Z. (2016). Kaposi's sarcoma herpesvirus (KSHV) microRNA K12-1 functions as an oncogene by activating NF-кB/IL-6/ STAT3 signaling. Oncotarget 7, 33363-33373. doi: 10.18632/oncotarget.9221

Cheong, W. C., Park, J. H., Kang, H. R., and Song, M. J. (2015). Downregulation of Poly(ADP-Ribose) Polymerase 1 by a viral processivity factor facilitates lytic replication of gammaherpesvirus. J. Virol. 89, 9676-9682. doi: 10.1128/JVI. 00559- 15

Cohen, A., Bordie, C., and Sarid, R. (2006). An essential role of ERK signalling in TPA-induced reactivation of Kaposi's sarcoma-associated herpesvirus. J. Gen. Virol. 87, 795-802. doi: 10.1099/vir.0.81619-0

Cole, S. W., Kemeny, M. E., Fahey, J. L., Zack, J. A., and Naliboff, B. D. (2003). Psychological risk factors for HIV pathogenesis: mediation by the autonomic nervous system. Biol. Psychiatry 54, 1444-1456. doi: 10.1016/S0006-3223(02) 01888-7

Dai, W., Jia, Q., Bortz, E., Shah, S., Liu, J., Atanasov, I., et al. (2008). Unique structures in a tumor herpesvirus revealed by cryo-electron tomography and microscopy. J. Struct. Biol. 161, 428-438. doi: 10.1016/j.jsb.2007.10.010

Dai, X., Gong, D., Wu, T. T., Sun, R., and Zhou, Z. H. (2014). Organization of capsid-associated tegument components in Kaposi's sarcoma-associated herpesvirus. J. Virol. 88, 12694-12702. doi: 10.1128/JVI.01509-14

Dai, X., Gong, D., Xiao, Y., Wu, T. T., Sun, R., and Zhou, Z. H. (2015). CryoEM and mutagenesis reveal that the smallest capsid protein cements and stabilizes Kaposi's sarcoma-associated herpesvirus capsid. Proc. Natl. Acad. Sci. U.S.A. 112, E649-E656. doi: 10.1073/pnas.1420317112

Davis, D. A., Rinderknecht, A. S., Zoeteweij, J. P., Aoki, Y., Read-Connole, E. L., Tosato, G., et al. (2001). Hypoxia induces lytic replication of Kaposi sarcomaassociated herpesvirus. Blood 97, 3244-3250. doi: 10.1182/blood.V97.10.3244

Davis, Z. H., Hesser, C. R., Park, J., and Glaunsinger, B. A. (2015a). Interaction between ORF24 and ORF34 in the Kaposi's sarcoma-associated herpesvirus late gene transcription factor complex is essential for viral late gene expression. J. Virol. 90, 599-604. doi: 10.1128/JVI.02157-15

Davis, Z. H., Verschueren, E., Jang, G. M., Kleffman, K., Johnson, J. R., Park, J., et al. (2015b). Global mapping of herpesvirus-host protein complexes reveals a transcription strategy for late genes. Mol. Cell. 57, 349-360. doi: 10.1016/j. molcel.2014.11.026

Deng, B., O’Connor, C. M., Kedes, D. H., and Zhou, Z. H. (2007). Direct visualization of the putative portal in the Kaposi's sarcoma-associated herpesvirus capsid by cryoelectron tomography. J. Virol. 81, 3640-3644. doi: 10.1128/JVI.02254-06

DePamphilis, M. L. (1993). Origins of DNA replication that function in eukaryotic cells. Curr. Opin. Cell Biol. 5, 434-441. doi: 10.1016/0955-0674(93)90008-E

Di Bartolo, D. L., Hyjek, E., Keller, S., Guasparri, I., Deng, H., Sun, R., et al. (2009). Role of defective Oct-2 and OCA-B expression in immunoglobulin production and Kaposi's sarcoma-associated herpesvirus lytic reactivation in primary effusion lymphoma. J. Virol. 83, 4308-4315. doi: 10.1128/JVI. 02196-08 
Ehrlich, E. S., Chmura, J. C., Smith, J. C., Kalu, N. N., and Hayward, G. S. (2014). KSHV RTA abolishes NFKB responsive gene expression during lytic reactivation by targeting vFLIP for degradation via the proteasome. PLOS ONE 9:e91359. doi: 10.1371/journal.pone.0091359

Epelbaum, O., Go, R., Patel, G., and Braman, S. (2016). Pulmonary Kaposi's sarcoma and its complications in the HAART era: a contemporary case-based review. Lung 194, 163-169. doi: 10.1007/s00408-015-9830-7

Feske, S., Okamura, H., Hogan, P. G., and Rao, A. (2003). Ca2+/calcineurin signalling in cells of the immune system. Biochem. Biophys. Res. Commun. 311, 1117-1132. doi: 10.1016/j.bbrc.2003.09.174

Fruehauf, J. P., and Meyskens, L. F. Jr. (2007). Reactive oxygen species: a breath of life or death? Clin. Cancer Res. 13, 789-794. doi: 10.1158/1078-0432.ccr-062082

Giffin, L., and Damania, B. (2014). KSHV: pathways to tumorigenesis and persistent infection. Adv. Virus Res. 88, 111-159. doi: 10.1016/B978-0-12800098-4.00002-7

Gil, L., Martínez, G., González, I., Tarinas, A., Alvarez, A., Giuliani, A., et al. (2003). Contribution to characterization of oxidative stress in HIV/AIDS patients. Pharmacol. Res. 47, 217-224. doi: 10.1016/S1043-6618(02)00320-1

Gonzalez-Molleda, L., Wang, Y., and Yuan, Y. (2012). Potent antiviral activity of topoisomerase I and II inhibitors against Kaposi's sarcoma-associated herpesvirus. Antimicrobe Agents Chemother. 56, 893-902. doi: 10.1128/AAC. 05274- 11

Goodwin, D. J., Walters, M. S., Smith, P. G., Thurau, M., Fickenscher, H., and Whitehouse, A. (2001). Herpesvirus saimiri open reading frame 50 (Rta) protein reactivates the lytic replication cycle in a persistently infected A549 cell line. J. Virol. 75, 4008-4013. doi: 10.1128/JVI.75.8.4008-4013.2001

Gottwein, E., Corcoran, D. L., Mukherjee, N., Skalsky, R. L., Hafner, M., Nusbaum, J. D., et al. (2011). Viral microRNA targetome of KSHV-infected primary effusion lymphoma cell lines. Cell Host Microbe 10, 515-526. doi: 10.1016/j. chom.2011.09.012

Gottwein, E., and Cullen, B. R. (2008). Viral and cellular microRNAs as determinants of viral pathogenesis and immunity. Cell Host Microbe 3, 375-387. doi: 10.1016/j.chom.2008.05.002

Gottwein, E., Mukherjee, N., Sachse, C., Frenzel, C., Majoros, W. H., Chi, J. T., et al. (2007). A viral microRNA functions as an ortholog of cellular miR-155. Nature 13, 1096-1099. doi: 10.1038/nature05992

Gould, F., Harrison, S. M., Hewitt, E. W., and Whitehouse, A. (2009). Kaposi's sarcoma-associated herpesvirus RTA promotes degradation of the Heyl repressor protein through the ubiquitin proteasome pathway. J. Virol. 83, 6727-6738. doi: 10.1128/JVI.00351-09

Gradoville, L., Gerlach, J., Grogan, E., Shedd, D., Nikiforow, S., Metroka, C., et al. (2000). Kaposi's sarcoma-associated herpesvirus open reading frame 50/Rta protein activates the entire lytic cycle in the $\mathrm{HH}-\mathrm{B} 2$ primary effusion lymphoma cell line. J. Virol. 74, 6207-6212. doi: 10.1128/JVI.74.13.6207-6212.2000

Gregory, S. M., West, J. A., Dillon, P. J., Hilscher, C., Dittmer, D. P., and Damania, B. (2009). Toll-like receptor signaling controls reactivation of KSHV from latency. Proc. Natl. Acad. Sci. U.S.A. 106, 11725-11730. doi: 10.1073/pnas. 0905316106

Griffin, L. D., Wilson, S. J., and Kellam, P. (2009). X-box binding protein 1 contributes to induction of the Kaposi's sarcoma-associated herpesvirus lytic cycle under hypoxic conditions. J. Virol. 83, 7202-7209. doi: 10.1128/JVI. 00076-09

Grundhoff, A., and Ganem, D. (2004). Inefficient establishment of KSHV latency suggests an additional role for continued lytic replication in Kaposi sarcoma pathogenesis. J. Clin. Invest. 113, 124. doi: 10.1172/jci200417803

Guasparri, I., Keller, S. A., and Cesarman, E. (2004). KSHV vFLIP is essential for the survival of infected lymphoma cells. J. Exp. Med. 199, 993-1003. doi: $10.1084 /$ jem.20031467

Guihot, A., Dupin, N., Marcelin, A. G., Isabelle, G., Bedin, A. S., Bossi, P., et al. (2006). Low $T$ cell responses to human herpesvirus 8 in patients with AIDS related and classic Kaposi sarcoma. J. Infect. Dis. 194, 1078-1088. doi: 10.1086/ 507648

Guito, J., Gavina, A., Palmeri, D., and Lukac, D. M. (2014). The cellular peptidylprolyl cis/trans isomerase Pin1 regulates reactivation of Kaposi's sarcomaassociated herpesvirus from latency. J. Virol. 88, 547-558. doi: 10.1128/JVI. 02877-13
Guito, J., and Lukac, D. M. (2012). KSHV Rta promoter specification and viral reactivation. Front. Microbiol. 3:30. doi: 10.3389/fmicb.2012.00030

Guito, J., and Lukac, D. M. (2015). KSHV reactivation and novel implications of protein isomerization on lytic switch control. Viruses 7, 72-109. doi: 10.3390/ v7010072

Gunther, T., and Grundhoff, A. (2010). The epigenetic landscape of latent Kaposi sarcoma- associated herpesvirus genomes. PLoS Pathog. 6:e1000935. doi: 10. 1371/journal.ppat.1000935

Guo, H., Wang, L., Peng, L., Zhou, Z. H., and Deng, H. (2009). Open reading frame 33 of a gammaherpesvirus encodes a tegument protein essential for virion morphogenesis and egress. J. Virol. 83, 10582-10595. doi: 10.1128/JVI.00497-09

Guo, H.-G., Patti, S., Sadowska, M., Charurat, M., and Reitz, M. (2004). Tumorigenesis by human herpesvirus 8 vGPCR is accelerated by human immuodeficiency virus type 1 Tat. J. Virol. 78, 9336-9342. doi: 10.1128/JVI.78. 17.9336-9342.2004

Guo, H. G., Sadowska, M., Reid, W., Tschachler, E., Hayward, G., and Reitz, M. (2003). Kaposi's sarcoma-like tumors in a human herpesvirus 8 ORF74 transgenic mouse. J. Virol. 77, 2631-2639. doi: 10.1128/JVI.77.4.2631-2639. 2003

Gwack, Y., Baek, H. J., Nakamura, H., Lee, S. H., Meisterernst, M., Roeder, R. G., et al. (2003a). Principal role of TRAP/mediator and SWI/SNF complexes in Kaposi's sarcoma-associated herpesvirus RTA-mediated lytic reactivation. Mol. Cell. Biol. 23, 2055-2067.

Gwack, Y., Nakamura, H., Lee, S. H., Souvlis, J., Yustein, J. T., Gygi, S., et al. (2003b). Poly(ADP-ribose) polymerase 1 and Ste20-like kinase hKFC act as transcriptional repressors for gamma-2 herpesvirus lytic replication. Mol. Cell. Biol. 23, 8282-8294.

Haque, M., Wang, V., Davis, D. A., Zheng, Z.-M., and Yarchoan, R. (2006). Genetic organization and hypoxic activation of the Kaposi's sarcoma-associated herpesvirus ORF34-37 gene cluster. J. Virol. 80, 7037-7051. doi: 10.1128/JVI. 00553-06

Harrington, W. Jr., Sieczkowski, L., Sosa, C., Chan-a-Sue, S., Cai, J. P., Cabral, L., et al. (1997). Activation of HHV-8 by HIV-1 tat. Lancet 349, 774-775. doi: 10.1016/S0140-6736(05)60199-7

Harrison, S. M., and Whitehouse, A. (2008). Kaposi's sarcoma-associated herpesvirus (KSHV) Rta and cellular HMGB1 proteins synergistically transactivate the KSHV ORF50 promoter. FEBS Lett. 582, 3080-3084. doi: 10.1016/j.febslet.2008.07.055

Homa, F. L., Otal, T. M., Glorioso, J. C., and Levine, M. (1986). Transcriptional control signals of a herpes simplex virus type 1 late (gamma 2) gene lie within bases -34 to +124 relative to the 5' terminus of the mRNA. Mol. Cell. Biol. 6, 3652-3666. doi: 10.1128/MCB.6.11.3652

Huang, L. M., Chao, M. F., Chen, M. Y., Shih, H. M., Chiang, Y. P., Chuang, C. Y., et al. (2001). Reciprocal regulatory interaction between human herpesvirus 8 and human immunodeficiency virus type 1. J. Biol. Chem. 276, 13427-13432. doi: 10.1074/jbc.M011314200

Hyun, T. S., Subramanian, C., Cotter, M. A., Thomas, R. A., and Robertson, E. S. (2001). Latency-associated nuclear antigen encoded by Kaposi's sarcomaassociated herpesvirus interacts with Tat and activates the long terminal repeat of human immunodeficiency virus type 1 in human cells. J. Virol. 75, 8761-8771. doi: 10.1128/JVI.75.18.8761-8771.2001

Iroezindu, M. O. (2016). Disparities in the magnitude of human immunodeficiency virus-related opportunistic infections between high and low/middle-income countries: is highly active antiretroviral therapy changing the trend. Ann. Med. Health Sci. Res. 6, 4-18. doi: 10.4103/2141-9248.180234

Izumiya, Y., Izumiya, C., Hsia, D., Ellison, T. J., Luciw, P. A., and Kung, H. J. (2009). NF- $\mathrm{B}$ serves as a cellular sensor of Kaposi's sarcoma-associated herpesvirus latency and negatively regulates K-Rta by antagonizing the RBP-JK coactivator. J. Virol. 83, 4435-4446. doi: 10.1128/JVI.01999-08

Izumiya, Y., Kobayashi, K., Kim, K. Y., Pochampalli, M., Izumiya, C., Shevchenko, B., et al. (2013). Kaposi's sarcoma-associated herpesvirus K-Rta exhibits SUMO-targeting ubiquitin ligase (STUbL) like activity and is essential for viral reactivation. PLoS Pathog. 9:e1003506. doi: 10.1371/journal.ppat. 1003506

Jaber, T., and Yuan, Y. (2013). A virally encoded small peptide regulates RTA stability and facilitates Kaposi's sarcoma-associated herpesvirus lytic replication. J. Virol. 87, 3461-3470. doi: 10.1128/JVI.02746-12 
Jiang, Y., Xu, D., Zhao, Y., and Zhang, L. (2008). Mutual iinhibition between Kaposi's sarcoma-associated herpesvirus and Epstein-Barr virus lytic replication initiators in dually infected primary effusion lymphoma. PLOS ONE 3:e1569. doi: 10.1371/journal.pone.0001569

Johnson, P. A., and Everett, R. D. (1986). The control of herpes simplex virus type-1 late gene transcription: a TATA-box/cap site region is sufficient for fully efficient regulated activity. Nucleic Acids Res. 14, 8247-8264. doi: 10.1093/nar/ 14.21.8247

Jones, J. L., Hanson, D. L., Dworkin, M. S., and Jaffe, H. W. (2000). Incidence and trends in Kaposi's sarcoma in the era of effective antiretroviral therapy. J. Acquir. Immune Defic. Syndr. 24, 270-274. doi: 10.1097/00126334-20000701000013

Kang, H., Weidmer, A., Yuan, Y., and Lieberman, P. M. (2011). Coordination of KSHV latent and lytic gene control by CTCF-cohesin mediated chromosome conformation. PLoS Pathog. 7:e1002140. doi: 10.1371/journal.ppat.1002140

Karijolich, J., Zhao, Y., Peterson, B., Zhou, Q., and Glaunsinger, B. (2014). Kaposi's sarcoma-associated herpesvirus ORF45 mediates transcriptional activation of the HIV-1 long terminal repeat via RSK2. J. Virol. 88, 7024-7035. doi: 10.1128/ JVI.00931- 14

Keller, R., Zago, A., Viana, M. C., Bourboulia, D., Desgranges, C., Casseb, J., et al. (2001). HHV-8 infection in patients with AIDS-related Kaposi's sarcoma in Brazil. Braz. J. Med. Biol. Res. 34, 879-886. doi: 10.1590/S0100879X2001000700007

Kimball, L. E., Casper, C., Koelle, D. M., Morrow, R., Corey, L., and Vieira, J. (2004). Reduced levels of neutralizing antibodies to Kaposi sarcoma-associated herpesvirus in persons with a history of Kaposi sarcoma. J. Infect. Dis. 189, 2016-2022. doi: 10.1086/386371

King, C. A., Li, X., Barbachano-Guerrero, A., and Bhaduri-McIntosh, S. (2015). STAT3 regulates lytic activation of Kaposi's sarcoma-associated herpesvirus. J. Virol. 89, 11347-11355. doi: 10.1128/JVI.02008-15

Konrad, A., Wies, E., Thurau, M., Marquardt, G., Naschberger, E., Hentschel, S., et al. (2009). A systems biology approach to identify the combination effects of human herpesvirus 8 genes on NF-кB activation. J. Virol. 83, 2563-2574. doi: 10.1128/JVI.01512-08

Lambert, M., Gannagé, M., Karras, A., Abel, M., Legendre, C., Kerob, D., et al. (2006). Differences in the frequency and function of HHV8-specific CD8 + T cells between asymptomatic HHV8 infection and Kaposi sarcoma. Blood 108, 3871-3880. doi: 10.1182/blood-2006-03-014225

Lan, K., Kuppers, D. A., and Robertson, E. S. (2005a). Kaposi's sarcomaassociated herpesvirus reactivation is regulated by interaction of latencyassociated nuclear antigen with recombination signal sequence-binding protein $\mathrm{J} \kappa$, the major downstream effector of the notch signaling pathway. J. Virol. 79, 3468-3478. doi: 10.1128/JVI.79.6.3468-3478.2005

Lan, K., Kuppers, D. A., Verma, S. C., Sharma, N., Murakami, M., and Robertson, E. S. (2005b). Induction of Kaposi's sarcoma-associated herpesvirus latencyassociated nuclear antigen by the lytic transactivator RTA: a novel mechanism for establishment of latency. J. Virol. 79, 7453-7465.

Lan, K., Kuppers, D. A., Verma, S. C., and Robertson, E. S. (2004). Kaposi's sarcoma-associated herpesvirus-encoded latency-associated nuclear antigen inhibits lytic replication by targeting Rta: a potential mechanism for virusmediated control of latency. J. Virol. 78, 6585-6594. doi: 10.1128/JVI.78.12. 6585-6594.2004

Lebbe, C., Blum, L., Pellet, C., Blanchard, G., Verola, O., Morel, P., et al. (1998). Clinical and biological impact of antiretroviral therapy with protease inhibitors on HIV-related Kaposi's sarcoma. AIDS 12, F45-F49. doi: 10.1097/00002030199807000-00002

Lee, C. P., Liu, P. T., Kung, H. N., Su, M. T., Chua, H. H., Chang, Y. H., et al. (2012). The ESCRT machinery is recruited by the viral BFRF1 protein to the nucleusassociated membrane for the maturation of Epstein-Barr virus. PLoS Pathog. 8:e1002904. doi: 10.1371/journal.ppat.1002904

Lei, X., Bai, Z., Ye, F., Xie, J., Kim, C. G., Huang, Y., et al. (2010). Regulation of

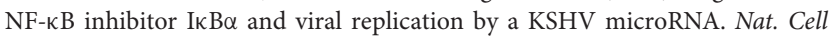
Biol. 12, 193-199. doi: 10.1038/ncb2019

Lei, X., Zhu, Y., Jones, T., Bai, Z., Huang, Y., and Gao, S. J. (2012). A KSHV microRNA and its variants target TGF-beta pathway to promote cell survival. J. Virol. 86, 11698-11711. doi: 10.1128/JVI.06855-11

Lepone, L., Rappocciolo, G., Knowlton, E., Jais, M., Piazza, P., Jenkins, F. J., et al. (2010). Monofunctional and polyfunctional CD8 $+\mathrm{T}$ cell responses to human herpesvirus 8 lytic and latency proteins. Clin. Vaccine Immunol. 17, 1507-1516. doi: 10.1128/CVI.00189-10

Li, D.-J., Verma, D., Mosbruger, T., and Swaminathan, S. (2014). CTCF and Rad21 act as host cell restriction factors for Kaposi's sarcoma-associated herpesvirus (KSHV) lytic replication by modulating viral gene transcription. PLoS Pathog. 10:e1003880. doi: 10.1371/journal.ppat.1003880

Li, Q., Zhou, F., Ye, F., and Gao, S. J. (2008). Genetic disruption of KSHV major latent nuclear antigen LANA enhances viral lytic transcriptional program. Virology 379, 234-244. doi: 10.1016/j.virol.2008.06.043

Li, W., Avey, D., Fu, B., Wu, J. J., Ma, S., Liu, X., et al. (2016). Kaposi's sarcomaassociated herpesvirus inhibitor of cGAS (KicGAS), encoded by ORF52, is an abundant tegument protein and is required for production of infectious progeny viruses. J. Virol. 90, 5329-5342. doi: 10.1128/JVI.02675-15

Li, X., Feng, J., and Sun, R. (2011). Oxidative stress induces reactivation of Kaposi's sarcoma-associated herpesvirus and death of primary effusion lymphoma cells. J. Virol. 85, 715-724. doi: 10.1128/JVI.01742-10

Liang, Y., Chang, J., Lynch, S. J., Lukac, D. M., and Ganem, D. (2002). The lytic switch protein of KSHV activates gene expression via functional interaction with RBP-Jkappa (CSL), the target of the notch signaling pathway. Genes Dev. 16, 1977-1989. doi: 10.1101/gad.996502

Liang, Y., and Ganem, D. (2003). Lytic but not latent infection by Kaposi's sarcoma-associated herpesvirus requires host CSL protein, the mediator of notch signaling. Proc. Natl. Acad. Sci. U.S.A. 100, 8490-8495. doi: 10.1073/pnas. 1432843100

Lieberman, P. M. (2013). Keeping it quiet: chromatin control of gammaherpesvirus latency. Nat. Rev. Microbiol. 11, 863-875. doi: 10.1038/nrmicro3135

Lin, C. L., Li, H., Wang, Y., Zhu, F. X., Kudchodkar, S., and Yuan, Y. (2003). Kaposi's sarcoma-associated herpesvirus lytic origin (ori-Lyt)-dependent DNA replication: identification of the ori-Lyt and association of K8 bZip protein with the origin. J. Virol. 77, 5578-5588. doi: 10.1128/JVI.77.10.5578-5588. 2003

Lin, H.-R., and Ganem, D. (2011). Viral microRNA target allows insight into the role of translation in governing microRNA target accessibility. Proc. Natl. Acad. Sci. U.S.A. 108, 5148-5153. doi: 10.1073/pnas.1102033108

Liu, C., Okruzhnov, Y., Li, H., and Nicholas, J. (2001). Human herpesvirus 8 (HHV-8)-encoded cytokines induce expression of and autocrine signaling by vascular endothelial growth factor (VEGF) in HHV-8-infected primaryeffusion lymphoma cell lines and mediate VEGF-independent antiapoptotic effects. J. Virol. 75, 10933-10940. doi: 10.1128/JVI.75.22.10933-10940.2001

Lu, C. C., Li, Z., Chu, C. Y., Feng, J., Feng, J., and Sun, R. (2010). MicroRNAs encoded by Kaposi's sarcoma-associated herpesvirus regulate viral life cycle. EMBO Rep. 11, 784-790. doi: 10.1038/embor.2010.132

Lu, F., Day, L., Gao, S. J., and Lieberman, P. M. (2006). Acetylation of the latencyassociated nuclear antigen regulates repression of Kaposi's sarcoma-associated herpesvirus lytic transcription. J. Virol. 80, 5273-5282. doi: 10.1128/JVI. 02541-05

Lu, F., Stedman, W., Yousef, M., Renne, R., and Lieberman, P. M. (2010). Epigenetic regulation of Kaposi's sarcoma-associated herpesvirus latency by virus-encoded microRNAs that target Rta and the cellular Rbl2-DNMT pathway. J. Virol. 84, 2697-2706. doi: 10.1128/JVI.01997-09

Lu, F., Zhou, J., Wiedmer, A., Madden, K., Yuan, Y., and Lieberman, P. M. (2003). Chromatin remodeling of the Kaposi's sarcoma-associated herpesvirus ORF50 promoter correlates with reactivation from latency. J. Virol. 77, 11425-11435. doi: 10.1128/JVI.77.21.11425-11435.2003

Lu, K. P., Finn, G., Lee, T. H., and Nicholson, L. K. (2007). Prolyl cis-trans isomerization as a molecular timer. Nat. Chem. Biol. 3, 619-629. doi: 10.1038/ nchembio. 2007.35

Lukac, D. M., Garibyan, L., Kirshner, J. R., Palmeri, D., and Ganem, D. (2001). DNA binding by Kaposi's sarcoma-associated herpesvirus lytic switch protein is necessary for transcriptional activation of two viral delayed early promoters. J. Virol. 75, 6786-6799. doi: 10.1128/JVI.75.15.6786-6799.2001

Lukac, D. M., Kirshner, J. R., and Ganem, D. (1999). Transcriptional activation by the product of the open reading frame 50 of Kaposi's-associated herpesvirus is required for lytic viral reactivation in B cells. J. Virol. 73, 9348-9361.

Lukac, D. M., Renne, R., Kirshner, J. R., and Ganem, D. (1998). Reactivation of Kaposi's sarcoma-associated herpesvirus infection from latency by expression of the ORF 50 transactivator, a homolog of the EBV R protein. Virology 52 , 304-312. doi: 10.1006/viro.1998.9486 
Lukac, D. M., and Yuan, Y. (2007). "Reactivation and lytic replication of KSHV," in Human Herpesviruses: Biology, Therapy, and Immunoprophylaxis, eds A. Arvin, G. Campadelli-Fiume, E. Mocarski, P. S. Moore, B. Roizman, R. Whitley, et al. (Cambridge: Cambridge University Press), 434-460. doi: 10. 1017/CBO9780511545313.027

Mallery, S. R., Pei, P., Landwehr, D. J., Clark, C. M., Bradburn, J. E., Ness, G. M., et al. (2004). Implications for oxidative and nitrative stress in the pathogenesis of AIDS-related Kaposi's sarcoma. Carcinogenesis 25, 597-603. doi: 10.1093/ carcin/bgh042

Manzano, M., Shamulailatpam, P., Raja, A. N., and Gottwein, E. (2013). Kaposi's sarcoma-associated herpesvirus encodes a mimic of cellular miR-23. J. Virol. 87, 11821-11830. doi: 10.1128/JVI.01692-13

Martin, D., Galisteo, R., Ji, Y., Montaner, S., and Gutkind, J. S. (2008). An NF- $\kappa$ B gene expression signature contributes to Kaposi's sarcoma virus vGPCRinduced direct and paracrine neoplasia. Oncogene 27, 1844-1852. doi: 10.1038/ sj.onc. 1210817

Martin, D. F., Kuppermann, B. D., Wolitz, R. A., Palestine, A. G., Li, H., and Robinson, C. A. (1999). Oral ganciclovir for patients with cytomegalovirus retinitis treated with a ganciclovir implant. Roche Ganciclovir Study Group. N. Engl. J. Med. 340, 1063-1070. doi: 10.1056/NEJM199904083401402

Martin, J. N., Ganem, D. E., Osmond, D. H., Page-Shafer, K. A., Macrae, D., and Kedes, D. H. (1998). Sexual transmission and the natural history of human herpesvirus 8 infection. N. Engl. J. Med. 338, 948-954. doi: 10.1056/ NEJM199804023381403

McCune, J. M. (2001). The dynamics of CD4+ T-cell depletion in HIV disease. Nature 410, 974-979. doi: 10.1038/35073648

McGeoch, D. J., and Davison, A. J. (1999). The descent of human herpesvirus 8. Semin. Cancer Biol. 9, 201-209. doi: 10.1006/scbi.1999.0093

Merat, R., Amara, A., Lebbe, C., de The, H., Morel, P., and Saib, A. (2002). HIV-1 infection of primary effusion lymphoma cell line triggers Kaposi's sarcomaassociated herpesvirus (KSHV) reactivation. Int. J. Cancer 97, 791-795. doi: $10.1002 /$ ijc. 10086

Mercader, M., Taddeo, B., Panella, J., Chandran, B., Nickoloff, B., and Foreman, K. (2000). Induction of HHV-8 lytic cycle replication by inflammatory cytokines produced by HIV-1-infected T cells. Am. J. Pathol. 156, 1961-1971. doi: 10. 1016/S0002-9440(10)65069-9

Mettenleiter, T. C. (2002). Herpesvirus assembly and egress. J. Virol. 76, 1537-1547. doi: 10.1128/JVI.76.4.1537-1547.2002

Mettenleiter, T. C., Klupp, B. G., and Granow, H. (2009). Herpesvirus assembly: an update. Virus Res. 143, 222-234. doi: 10.1016/j.virusres.2009.03.018

Miller, G., Heston, L., Grogan, E., Gradoville, L., Rigsby, M., Sun, R., et al. (1997). Selective switch between latency and lytic replication of Kaposi's sarcoma herpesvirus and Epstein-Barr virus in dually infected body cavity lymphoma cells. J. Virol. 71, 314-324.

Min, J., and Katzenstein, D. A. (1999). Detection of Kaposi's sarcoma-associated herpesvirus in peripheral blood cells in human immunodeficiency virus infection: association with Kaposi's sarcoma, CD4 cell count, and HIV RNA levels. AIDS Res. Hum. Retroviruses 15, 51-55. doi: 10.1089/088922299 311709

Mocroft, A., Kirk, O., Clumeck, N., Gargalianos-Kakolyris, P., Trocha, H., Chentsova, N., et al. (2004). The changing pattern of Kaposi sarcoma in patients with HIV, 1994-2003: the EuroSIDA Study. Cancer 100, 2644-2654. doi: 10. 1002/cncr.20309

Montaner, S., Sodhi, A., Molinolo, A., Bugge, T. H., Sawak, E. T., He, Y., et al. (2003). Endothelial infection with KSHV genes in vivo reveals that vGPCR initiates Kaposi's sarcomagenesis and can promote the tumorigenic potential of viral latent genes. Cancer Cell 3, 23-36. doi: 10.1016/S1535-6108(02) 00237-4

Myoung, J., and Ganem, D. (2011). Active lytic infection of human primary tonsillar B cells by KSHV and its noncytolytic control by activated CD4+ T cells. J. Clin. Invest. 1221, 1130-1140. doi: 10.1172/JCI43755

Nasti, G., Martellotta, F., Berretta, M., Mena, M., Fasan, M., Di Perri, G., et al. (2003). Impact of highly active antiretroviral therapy on the presenting features and outcome of patients with acquired immunodeficiency syndrome-related Kaposi sarcoma. Cancer 98, 2440-2446. doi: 10.1002/cncr.11816

Newcomb, W. W., Homa, F. L., Thomsen, D. R., Booy, F. P., Trus, B. L., Steven, A. C., et al. (1996). Assembly of the herpes simplex virus capsid: characterization of intermediates observed during cell-free capsid formation. J. Mol. Biol. 263, 432-446. doi: 10.1006/jmbi.1996.0587

Newcomb, W. W., Homa, F. L., Thomsen, D. R., Ye, Z., and Brown, J. C. (1994). Cell-free assembly of the herpes simplex virus capsid. J. Virol. 68, 6059-6063.

Pellet, C., Chevret, S., Blum, L., Gauville, C., Hurault, M., Blanchard, G., et al. (2001). Virologic and immunologic parameters that predict clinical response of AIDS-associated Kaposi's sarcoma to highly active antiretroviral therapy. J. Invest. Dermatol. 117, 858-863. doi: 10.1046/j.0022-202x.2001. 01465.x

Plaisance-Bonstaff, K., Choi, H. S., Beals, T., Krueger, B. J., Boss, I. W., Gay, L. A., et al. (2014). KSHV miRNAs decrease expression of lytic genes in latently infected PEL and endothelial cells by targeting host transcription factors. Viruses 6, 4005-4023. doi: 10.3390/v6104005

Potthoff, A., and Brockmeyer, N. H. (2007). HIV-associated Kaposi sarcoma: pathogenesis and therapy. J. Dtsch. Dermatol. Ges. 18, 1091-1094. doi: 10.1111/ j.1610-0387.2007.06567.x

Prakash, O., Tang, Z. Y., Peng, X., Roy, C., Gill, J., Farr, G., et al. (2002). Tumorigenesis and aberrant signaling in transgenic mice expressing the human herpesvirus-8 K1 gene. J. Natl. Cancer Inst. 94, 926-935. doi: 10.1093/jnci/94. 12.926

Ramirez, L., Cao, H., Nelson, D., Hammond, E., Lee, A.-H., Yoshida, H., et al. (2004). XBP1 is essential for survival under hypoxic conditions and is required for tumor growth. Cancer Res. 64, 5943-5947. doi: 10.1158/0008-5472.CAN04- 1606

Renne, R., Barry, C., Dittmer, D., Compitello, N., Brown, P. O., and Ganem, D. (2001). Modulation of cellular and viral gene expression by the latencyassociated nuclear antigen of Kaposi's sarcoma-associated herpesvirus. J. Virol. 75, 458-468. doi: 10.1128/JVI.75.1.458-468.2001

Renne, R., Lagunoff, M., Zhong, W., and Ganem, D. (1996). The size and conformation of Kaposi's sarcoma-associated herpesvirus (human herpesvirus 8) DNA in infected cells and virions. J. Virol. 70, 8151-8154.

Robey, R. C., Mletzko, S., and Gotch, F. M. (2010). The T-Cell immune response against Kaposi's sarcoma-associated herpesvirus. Adv. Virol. 2010, 1-9. doi: 10.1155/2010/340356

Rossetto, C. C., and Pari, G. (2012). KSHV PAN RNA associates with demethylases UTX and JMJD3 to activate lytic replication through a physical interaction with the virus genome. PLoS Pathog. 8:e1002680. doi: 10.1371/journal.ppat. 1002680

Rossetto, C. C., and Pari, G. (2014). PAN's Labyrinth: molecular biology of Kaposi's sarcoma-associated herpesvirus (KSHV) PAN RNA, a multifunctional long noncoding RNA. Viruses 6, 4212-4226. doi: 10.3390/v6114212

Rossetto, C. C., Tarrant-Elorza, M., Verma, S., Purushothaman, P., and Pari, G. (2013). Regulation of viral and cellular gene expression by Kaposi's sarcomaassociated herpesvirus polyadenylated nuclear RNA. J. Virol. 87, 5540-5553. doi: 10.1128/JVI.03111-12

Rozen, R., Sathish, N., Li, Y., and Yuan, Y. (2008). Virion-wide protein interactions of Kaposi's sarcoma-associated herpesvirus. J. Virol. 82, 4742-4750. doi: 10. 1128/JVI.02745-07

Sakakibara, S., Ueda, K., Chen, J., Okuno, T., and Yamanishi, K. (2001). Octamerbinding sequence is a key element for the autoregulation of Kaposi's sarcomaassociated herpesvirus ORF50/Lyta gene expression. J. Virol. 75, 6894-6900. doi: 10.1128/JVI.75.15.6894-6900.2001

Samaniego, F., Pati, S., Karp, J. E., Prakash, O., and Bose, D. (2000). Human herpesvirus 8 K1-associated nuclear factor-kappa B-dependent promoter activity: role in Kaposi's sarcoma inflammation? J. Natl. Cancer Inst. Monogr. 2000, 15-23. doi: 10.1093/oxfordjournals.jncimonographs.a 024252

Samols, M. A., Hu, J., Skalsky, R. L., and Renne, R. (2005). Cloning and identification of a microRNA cluster within the latency-associated region of Kaposi's sarcoma-associated herpesvirus. J. Virol. 79, 9301-9305. doi: 10.1128/ JVI.79.14.9301-9305.2005

Sathish, N., and Yuan, Y. (2011). Evasion and subversion of interferon-mediated antiviral immunity by Kaposi's sarcoma-associated herpesvirus: an overview. J. Virol. 85, 10934-10944. doi: 10.1128/JVI.00687-11

Sattler, C., Steer, B., and Adler, H. (2016). Multiple lytic origins of replication are required for optimal gammaherpesvirus fitness in vitro and in vivo. PLoS Pathog. 12:e1005510. doi: 10.1371/journal.ppat.1005510 
Saveliev, A., Zhu, F., and Yuan, Y. (2002). Transcription mapping and expression patterns of genes in the major immediate-early region of Kaposi's sarcomaassociated herpesvirus. Virology 299, 301-314. doi: 10.1006/viro.2002.1561

Seaman, W., Ye, D., Wang, R., Hale, E., Weisse, M., and Quinlivan, E. (1999). Gene expression from the ORF50/K8 region of Kaposi's sarcoma-associated herpesvirus. Virology 263, 436-449. doi: 10.1006/viro.1999.9963

Semenza, G. L. (1998). Hypoxia-inducible factor 1: master regulator of $\mathrm{O} 2$ homeostasis. Curr. Opin. Genet. Dev. 8, 588-594. doi: 10.1016/S0959-437X(98) 80016-6

Shelburne, S. A. III., and Hamill, R. J. (2003). The immune reconstitution inflammatory syndrome. AIDS Rev. 5, 67-79.

Shiels, M. S., Pfeiffer, R. M., Gail, M. H., Hall, H. I., Li, J., Chaturvedi, A. K., et al. (2011). Cancer burden in the HIV-infected population in the United States. J. Natl. Cancer Inst. 103, 753-762. doi: 10.1093/jnci/djr076

Simon, J. A., and Kingston, R. E. (2009). Mechanisms of polycomb gene silencing: knowns and unknowns. Nat. Rev. Mol. Cell Biol. 10, 697-708. doi: 10.1038/ nrm 2763

Sirianni, M. C., Vincenzi, L., Topino, S., Giovannetti, A., Mazzetta, F., Libi, F., et al. (2002). NK cell activity controls human herpesvirus 8 latent infection and is restored upon highly active antiretroviral therapy in AIDS patients with regressing Kaposi's sarcoma. Eur. J. Immunol. 32, 2711-2720. doi: 10.1002/ 1521-4141(2002010)32:10<2711::AID-IMMU2711>3.0.CO;2-3

Skalsky, R. L., Samols, M. A., Plaisance, K. B., Boss, I. W., Riva, A., Lopez, M. C., et al. (2007). Kaposi's sarcoma-associated herpesvirus encodes an ortholog of miR-155. J. Virol. 81, 12836-12845. doi: 10.1128/JVI.01804-07

Song, M. J., Li, X., Brown, H. J., and Sun, R. (2002). Characterization of interactions between RTA and the promoter of polyadenylated nuclear RNA in Kaposi's sarcoma-associated herpesvirus/human herpesvirus 8. J. Virol. 76, 5000-5013. doi: 10.1128/JVI.76.10.5000-5013.2002

Staskus, K. A., Zhong, W., Gebhard, K., Herndier, B., Wang, H., Renne, R., et al. (1997). Kaposi's sarcoma-associated herpesvirus gene expression in endothelial (spindle) tumor cells. J. Virol. 71, 715-719.

Stedman, W., Kang, H., Lin, S., Kissil, J. L., Bartolomei, M. S., and Lieberman, P. M. (2008). Cohesins localize with CTCF at the KSHV latency control region and at cellular c-myc and H19/Igf2 insulators. EMBO J. 27, 654-666. doi: 10.1038/ emboj.2008.1

Strickler, H. D., Goedert, J. J., Bethke, F. R., Trubey, C. M., O’Brien, T. R., Palefsky, J., et al. (1999). Human herpesvirus 8 cellular immune responses in homosexual men. J. Infect. Dis. 180, 1682-1685. doi: 10.1086/315056

Sun, Q., Matta, H., and Chaudhary, P. (2005). Kaposi's sarcoma associated herpes virus-encoded viral FLICE inhibitory protein activates transcription from HIV1 long terminal repeat via the classical NF-kappaB pathway and functionally cooperates with Tat. Retrovirology 2, 9-23. doi: 10.1186/1742-4690-2-9

Sun, R., Lin, S. F., Gradoville, L., Yuan, Y., Zhu, F., and Miller, G. (1998). A viral gene that activates lytic cycle expression of Kaposi's sarcoma-associated herpesvirus. Proc. Natl. Acad. Sci. U.S.A. 95, 10866-10871. doi: 10.1073/pnas. 95.18.10866

Sun, R., Lin, S.-F., Staskus, K., Gradoville, L., Grogan, E., Haase, A., et al. (1999). Kinetics of Kaposi's sarcoma-associated herpesvirus gene expression. J. Virol. $73,2232-2242$.

Tam, H. K., Zhang, Z. F., Jacobson, L. P., Margolick, J. B., Chmiel, J. S., Rinaldo, C., et al. (2002). Effect of highly active antiretroviral therapy on survival among HIV-infected men with Kaposi sarcoma or non-Hodgkin lymphoma. Int. J. Cancer 98, 916-922. doi: 10.1002/ijc.10274

Tang, Q., Qin, D., Lv, Z., Zhu, X., Ma, X., Yan, Q., et al. (2012). Herpes simplex virus type 2 triggers reactivation of Kaposi's sarcoma-associated herpesvirus from latency and collaborates with HIV-1 Tat. PLOS ONE 7:e31652. doi: 10. 1371/journal.pone. 0031652

Tang, S., Yamanegi, K., and Zheng, A. M. (2004). Requirement of a 12-base-pair TATT-containing sequence and viral lytic DNA replication in activation of the Kaposi's sarcoma-associated herpesvirus K8.1 late promoter. J. Virol. 78, 2609-2614. doi: 10.1128/JVI.78.5.2609-2614.2004

Tao, M., Patel, H., Farrokhran, S. B., Franklin, R., Semenza, G. L., Sodhi, A., et al. (2015). KSHV induces aerobic glycolysis and angiogenesis through HIF-1 dependent upregulation of pyruvate kinase 2 in Kaposi's sarcoma. Angiogenesis 18, 477-488. doi: 10.1007/s10456-015-9475-4

Tedeschi, R., Enbom, M., Bidoli, E., Linde, A., De Paoli, P., and Dillner, J. (2001). Viral load of human herpesvirus 8 in peripheral blood of human immunodeficiency virus-infected patients with Kaposi's sarcoma. J. Clin. Microbiol. 39, 4269-4273. doi: 10.1128/JCM.39.12.4269-4273.2001

Thakker, S., and Verma, S. C. (2016). Co-infections and pathogenesis of KSHVassociated malignancies. Front. Microbiol. 7:151. doi: 10.3389/fmicb.2016. 00151

Toth, Z., Brulois, K., Lee, H. R., Izumiya, Y., Tepper, C., Kung, H. J., et al. (2013). Biphasic euchromatin-to-heterochromatin transition on the KSHV genome following de novo infection. PLOS Pathog. 9:e1003813. doi: 10.1371/journal. ppat.1003813

Toth, Z., Maglinte, D. T., Lee, S. H., Lee, H. R., Wong, L. Y., Brulois, K. F., et al. (2010). Epigenetic analysis of KSHV latent and lytic genomes. PLoS Pathog. 6:e1001013. doi: 10.1371/journal.ppat.1001013

Trus, B. L., Heymann, J. B., Nealon, K., Cheng, N., Newcomb, W. W., Brown, J. C., et al. (2001). Capsid structure of Kaposi's sarcoma-associated herpesvirus, a gammaherpesvirus, compared to those of an alphaherpesvirus, herpes simplex virus type 1, and a betaherpesvirus, cytomegalovirus. J. Virol. 75, 2879-2890. doi: 10.1128/JVI.75.6.2879-2890.2001

Uldrick, T. S., Wang, V., O’Mahony, D., Aleman, K., Wyvill, K. M., Marshall, V., et al. (2010). An interleukin-6-related systemic inflammatory syndrome in patients co-infected with Kaposi sarcoma-associated herpesvirus and HIV but without Multicentric Castleman disease. Clin. Infect. Dis. 51, 350-358. doi: $10.1086 / 654798$

Uppal, T., Jha, H. C., Verma, S. C., and Robertson, E. S. (2015). Chromatinization of the KSHV genome during the KSHV life cycle. Cancers 7, 112-142. doi: $10.3390 /$ cancers7010112

Varthakavi, V., Browning, P. J., and Spearman, P. (1999). Human immunodeficiency virus replication in a primary effusion lymphoma cell line stimulates lytic-phase replication of Kaposi's sarcoma-associated herpesvirus. J. Virol. 73, 10329-10338.

Varthakavi, V., Smith, R. M., Deng, H., Sun, R., and Spearman, P. (2002). Human immunodeficiency virus type-1 activates lytic cycle replication of Kaposi's sarcoma-associated herpesvirus through induction of KSHV Rta. Virology 297, 270-280. doi: 10.1006/viro.2002.1434

Vieira, J., O'Hearn, P., Kimball, L., Chandran, B., and Corey, L. (2001). Activation of Kaposi's sarcoma-associated herpesvirus (human herpesvirus 8) lytic replication by human cytomegalovirus. J. Virol. 75, 1378-1386. doi: 10. 1128/JVI.75.3.1378-1386.2001

Votteler, J., and Sundquist, W. I. (2013). Virus Budding and the ESCRT Pathway. Cell Host Microbe 14, 232-241. doi: 10.1016/j.chom.2013.08.012

Wang, F. Z., Akula, S. M., Pramod, N. P., Zeng, L., and Chandran, B. (2001). Human herpesvirus 8 envelope glycoprotein K8.1A interaction with the target cells involves heparan sulfate. J. Virol. 75, 7517-7527. doi: 10.1128/JVI.75.16. 7517-7527.2001

Wang, H., Zou, J., Zhao, B., Johannsen, E., Ashworth, T., Wong, H., et al. (2011). Genome-wide analysis reveals conserved and divergent features of Notch1/RBPJ binding in human and murine T-lymphoblastic leukemia cells. Proc. Natl. Acad. Sci. U.S.A. 108, 14908-14913. doi: 10.1073/pnas.1109 023108

Wang, L., Guo, H., Reyes, N., Lee, S., Bortz, E., Guo, F., et al. (2012). Distinct domains in ORF52 tegument protein mediate essential functions in murine gammaherpesvirus 68 virion tegumentation and secondary envelopment. J. Virol. 86, 1348-1357. doi: 10.1128/JVI.05497-11

Wang, S. E., Wu, F. Y., Chen, H., Shamay, M., Zheng, Q., and Hayward, G. (2004). Early activation of the Kaposi's sarcoma-associated herpesvirus RTA, RAP, and MTA promoters by the tetradecanoyl phorbol acetate-induced AP1 pathway. J. Virol. 78, 4248-4267. doi: 10.1128/JVI.78.8.4248-4267.2004

Wang, S. E., Wu, F. Y., Fujimuro, M., Zong, J., Hayward, S. D., and Hayward, G. S. (2003a). Role of CCAAT/enhancer-binding protein alpha (C/EBPalpha) in activation of the Kaposi's sarcoma-associated herpesvirus (KSHV) lytic-cycle replication-associated protein (RAP) promoter in cooperation with the KSHV replication and transcription activator (RTA) and RAP. J. Virol. 77, 600-623. doi: 10.1128/JVI.77.1.600-623.2003

Wang, S. E., Wu, F. Y., Yu, Y., and Hayward, G. S. (2003b). CCAAT/enhancerbinding protein-alpha is induced during the early stages of Kaposi's sarcomaassociated herpesvirus (KSHV) lytic cycle reactivation and together with the KSHV replication and transcription activator (RTA) cooperatively stimulates the viral RTA, MTA, and PAN promoters. J. Virol. 7, 9590-9612. doi: 10.1128/ JVI.77.17.9590-9612.2003 
Wang, X., Zhu, N., Li, W., Zhu, F., Wang, Y., and Yuan, Y. (2015). Monoubiquitylated ORF45 mediates association of KSHV particles with internal lipid rafts for viral assembly and egress. PLoS Pathog. 11:e1005332. doi: 10.1371/ journal.ppat.1005332

Wang, Y., Li, H., Chan, M. Y., Zhu, F. X., Lukac, D. M., and Yuan, Y. (2004). Kaposi's sarcoma-associated herpesvirus ori-Lyt-dependent DNA replication: cis-acting requirements for replication and ori-Lyt-associated RNA transcription. J. Virol. 78, 8615-8629. doi: 10.1128/JVI.78.16.8615-8629.2004

Wang, Y., Li, H., Tang, Q., Maul, G. G., and Yuan, Y. (2008). Kaposi's sarcomaassociated herpesvirus ori-Lyt-dependent DNA replication: involvement of host cellular factors. J. Virol. 82, 2867-2882. doi: 10.1128/JVI.01319-07

Wang, Y., Tang, Q., Maul, G. G., and Yuan, Y. (2006). Kaposi's sarcoma-associated herpesvirus ori-Lyt-dependent DNA replication: dual roles of RTA in the replication. J. Virol. 80, 12171-12186. doi: 10.1128/JVI.00990-06

Wang, Y., and Yuan, Y. (2007). Essential role of RBP-JK in activation of the K8 delayed-early promoter of Kaposi's sarcoma-associated herpesvirus by ORF50/RTA. Virology 359, 19-27. doi: 10.1016/j.virol.2006.09.032

Wedemeyer, W. J., Welker, E., and Scheraga, H. A. (2002). Proline cis-trans isomerization and protein folding. Biochemistry 41, 14637-14644. doi: 10.1021/ bi020574b

Wen, H. J., Minhas, V., and Wood, C. (2009). Identification and characterization of a new Kaposi's sarcoma-associated herpesvirus replication and transcription activator (RTA)-responsive element involved in RTA-mediated transactivation. J. Gen. Virol. 90, 944-953. doi: 10.1099/vir.2008.006817-0

West, J. T., and Wood, C. (2003). The role of Kaposi's sarcoma-associated herpesvirus/human herpesvirus-8 regulator of transcription activation (RTA) in control of gene expression. Oncogene 22, 5150-5163. doi: 10.1038/sj.onc. 1206555

Whitby, D., Howard, M. R., Tenant-Flowers, M., Brink, N. S., Copas, A., Boshoff, C., et al. (1995). Detection of Kaposi sarcoma associated herpesvirus in peripheral blood of HIV-infected individuals and progression to Kaposi's sarcoma. Lancet 346, 799-802. doi: 10.1016/S0140-6736(95)91619-9

Wilkinson, J., Cope, A., Gill, J., Bourboulia, D., Hayes, P., Imami, N., et al. (2002). Identification of Kaposi's sarcoma-associated herpesvirus (KSHV)specific cytotoxic T-lymphocyte epitopes and evaluation of reconstitution of KSHV-specific responses in human immunodeficiency virus type 1-infected patients receiving highly active antiretroviral therapy. J. Virol. 76, 2634-2640. doi: 10.1128/JVI.76.6.2634-2640.2002

Wilson, S. J., Tsao, E. H., Webb, B. L. J., Ye, H., Dalton-Griffin, L., Tsantoulas, C., et al. (2007). X box binding protein XBP-1 transactivates the Kaposi's sarcoma-associated herpesvirus (KSHV) ORF50 promoter, linking plasma cell differentiation to KSHV reactivation from latency. J. Virol. 81, 13578-13586. doi: 10.1128/JVI.01663-07

Wu, F. Y., Ahn, J. H., Alcendor, D. J., Jang, W. J., Xiao, J., Hayward, S. D., et al. (2001). Origin-independent assembly of Kaposi's sarcoma-associated herpesvirus DNA replication compartments in transient cotransfection assays and association with the ORF-K8 protein and cellular PML. J. Virol. 75, 1487-1506. doi: 10.1128/JVI.75.3.1487-1506.2001

Wu, F. Y., Chen, H., Wang, W. E., ApRhys, C. M., Gangling, L., Fujimuro, M., et al. (2003a). CCAAT/enhancer binding protein interacts with ZTA and mediates ZTA-induced p21CIP-1 accumulation and G1 cell cycle arrest during the Epstein-Barr virus lytic cycle. J. Virol. 77, 1481-1500.

Wu, F. Y., Wang, S. E., Tang, Q. Q., Fujimuro, M., Chiou, C. J., Zheng, Q., et al. (2003b). Cell cycle arrest by Kaposi's sarcoma-associated herpesvirus replication-associated protein is mediated at both the transcriptional and posttranslational levels by binding to CCAAT/enhancer-binding protein alpha and p21 (CIP-1). J. Virol. 77, 8893-8914. doi: 10.1128/JVI.77.16.8893-8914.2003

Wu, J. J., Avey, D., Li, W., Gillen, J., Fu, B., Miley, W., et al. (2015a). ORF33 and ORF38 of Kaposi's sarcoma-associated herpesvirus interact and are required for optimal production of infectious progeny viruses. J. Virol. 90, 1741-1756. doi: 10.1128/JVI.02738-15

Wu, J. J., Li, W., Shao, Y., Avey, D., Fu, B., Gillen, J., et al. (2015b). Inhibition of cGAS DNA sensing by a herpesvirus virion protein. Cell Host Microbe 18, 333-344. doi: 10.1016/j.chom.2015.07.015

Wu, T. T., Usherwood, E. J., Stewart, J. P., Nash, A. A., and Sun, R. (2000). Rta of murine gammaherpesvirus 68 reactivates the complete lytic cycle from latency. J. Virol. 74, 3659-3667. doi: 10.1128/JVI.74.8.3659-3667.2000
Xie, J., Ajibade, A. O., Ye, F., Kuhne, K., and Gao, S. J. (2008). Reactivation of Kaposi's sarcoma-associated herpesvirus from latency requires MEK/ERK, JNK and p38 multiple mitogen-activated protein kinase pathways. Virology 371, 139-154. doi: 10.1016/j.virol.2007.09.040

$\mathrm{Xu}$, Y., and Ganem, D. (2010). Making sense of antisense: seemingly noncoding RNAs antisense to the master regulator of Kaposi's sarcoma-associated herpesvirus lytic replication do not regulate that transcript but serve as mRNAs encoding small peptides. J. Virol. 84, 5465-5475. doi: 10.1128/JVI. 02705-09

Xu, Y., Rodriguez-Huete, A., and Pari, G. S. (2006). Evaluation of lytic origins of replication of Kaposi's sarcoma-associated herpesvirus/human herpesvirus 8 in the context of the viral genome. J. Virol. 80, 9905-9909. doi: 10.1128/JVI. 01004-06

Yang, T. Y., Chen, S. C., Leach, M. W., Manfra, D., Homey, B., Wiekowski, M., et al. (2000). Transgenic expression of the chemokine receptor encoded by human herpesvirus 8 induces an angioproliferative disease resembling Kaposi's sarcoma. J. Exp. Med. 191, 445-454. doi: 10.1084/jem.191. 3.445

Yang, Z., Yan, Z., and Wood, C. (2008). Kaposi's sarcoma-associated herpesvirus transactivator RTA promotes degradation of the repressors to regulate viral lytic replication. J. Virol. 82, 3590-3603. doi: 10.1016/j.virol.2009. 06.014

Ye, F., Zhou, F., Bedolla, R. G., Jones, T., Lei, X., Kang, T., et al. (2011). Reactive oxygen species hydrogen peroxide mediates Kaposi's sarcoma-associated herpesvirus reactivation from latency. PLoS Pathog. 7:e1002054. doi: 10.1371/ journal.ppat.1002054

Ye, F. C., Zhou, F. C., Xie, J. P., Kang, T., Greene, W., Kuhne, K., et al. (2008). Kaposi's sarcoma-associated herpesvirus latent gene vFLIP inhibits viral lytic replication through NF-kappaB-mediated suppression of the AP-1 pathway: a novel mechanism of virus control of latency. J. Virol. 82, 4235-4249. doi: 10.1128/JVI.02370-07

Yu, F., Harada, J. N., Brown, H. J., Deng, H., Song, M. J., Wu, T.-T., et al. (2007). Systematic identification of cellular signals reactivating Kaposi sarcoma-associated herpesvirus. PLoS Pathog. 3:e4411. doi: 10.1371/journal. ppat.0030044

Yu, Y., Wang, S. E., and Hayward, G. S. (2005). The KSHV immediate-early transcription factor RTA encodes ubiquitin E3 ligase activity that targets IRF7 for proteasome-mediated degradation. Immunity 22, 59-70. doi: 10.1016/j. immuni.2004.11.011

Zeng, Y., Zhang, X., Huang, Z., Cheng, L., Yao, S., Qin, D., et al. (2007). Intracellular Tat of human immunodeficiency virus type 1 activates lytic cycle replication of Kaposi's sarcoma-associated herpesvirus role of JAK/STAT signaling. J. Virol. 81, 2401-2417. doi: 10.1128/JVI.02024-06

Zhang, L., Zhu, C., Guo, Y., Wei, F., Lu, J., Qin, J., et al. (2014). Inhibition of KAP1 enhances hypoxia-induced Kaposi's sarcoma-associated herpesvirus reactivation through RBP-Jк. J. Virol. 88, 6873-6884. doi: 10.1128/JVI. 00283-14

Zhong, W., Wang, H., Herndier, B., and Ganem, D. (1996). Restricted expression of Kaposi sarcoma-associated herpesvirus (human herpesvirus 8) genes in Kaposi sarcoma. Proc. Natl. Acad. Sci. U.S.A. 93, 6641-6646. doi: 10.1073/pnas.93.13. 6641

Zhou, Z., Chen, D., Jakana, J., Rixon, F. J., and Chiu, W. (1999). Visualization of tegument-capsid interactions and DNA in intact herpes simplex virus type 1 virions. J. Virol. 73, 3210-3218.

Zhu, F., Cusano, T., and Yuan, Y. (1999). Identification of the immediate-early transcripts of Kaposi's sarcoma-associated herpesvirus. J. Virol. 73, 5556-5567.

Zhu, F. X., Chong, J. M., Wu, L., and Yuan, Y. (2005). Virion proteins of Kaposi's sarcoma-associated herpesvirus. J. Virol. 79, 800-811. doi: 10.1128/JVI.79.2. 800-811.2005

Zhu, F. X., King, S. M., Smith, E. J., Levy, D. E., and Yuan, Y. (2002). A Kaposi's sarcoma-associated herpesviral protein inhibits virus-mediated induction of type I interferon by blocking IRF-7 phosphorylation and nuclear accumulation. Proc. Natl. Acad. Sci. U.S.A. 99, 5573-5578. doi: 10.1073/pnas.082 420599

Zhu, F. X., Sathish, N., and Yuan, Y. (2010). Antagonism of host antiviral responses by Kaposi's sarcoma-associated herpesvirus tegument protein ORF45. PLoS ONE 5:e10573. doi: 10.1371/journal.pone.0010573 
Zhu, X., Guo, Y., Yao, S., Yan, Q., Xue, M., Hao, T., et al. (2014). Synergy between Kaposi's sarcoma-associated herpesvirus (KSHV) vIL-6 and HIV1 Nef protein in promotion of angiogenesis and oncogenesis: role of the AKT signaling pathway. Oncogene 33, 1986-1996. doi: 10.1038/onc. 2013.136

Zoeteweij, J. P., Moses, A. V., Rinderknecht, A. S., Davis, D. A., Overwijk, W. W., Yarchoan, R., et al. (2001). Targeted inhibition of calcineurin signaling blocks calcium-dependent reactivation of Kaposi sarcomaassociated herpesvirus. Blood 97, 2374-2380. doi: 10.1182/blood.V97. 8.2374
Conflict of Interest Statement: The authors declare that the research was conducted in the absence of any commercial or financial relationships that could be construed as a potential conflict of interest.

Copyright (c) 2017 Aneja and Yuan. This is an open-access article distributed under the terms of the Creative Commons Attribution License (CC BY). The use, distribution or reproduction in other forums is permitted, provided the original author(s) or licensor are credited and that the original publication in this journal is cited, in accordance with accepted academic practice. No use, distribution or reproduction is permitted which does not comply with these terms. 